\title{
Mitophagy contributes to alpha-tocopheryl succinate toxicity in GSNOR-deficient hepatocellular carcinoma.
}

Salvatore Rizza ${ }^{1^{*}}$, Luca Di Leo ${ }^{2}$, Sara Mandatori ${ }^{3}$, Daniela De Zio ${ }^{2}$, Giuseppe Filomeni ${ }^{14^{*}}$.

${ }^{1}$ Redox Signaling and Oxidative Stress Group, Danish Cancer Society Research Center, 2100 Copenhagen, Denmark.

${ }^{2}$ Cell Stress and Survival Unit, Danish Cancer Society Research Center, 2100 Copenhagen, Denmark.

${ }^{3}$ Department of Anatomical, Histological, Forensic Medicine and Orthopedic Sciences, Sapienza University of Rome, 00161 Rome, Italy.

${ }^{4}$ Department of Biology, Tor Vergata University of Rome, 00133 Rome, Italy.

*To whom correspondence should be addressed:

Salvatore Rizza, rizza@cancer.dk; Giuseppe Filomeni, giufil@cancer.dk 


\section{Abstract}

The denitrosylating enzyme $S$-nitrosoglutathione reductase (GSNOR), has been reported to control the selective degradation of mitochondria through mitophagy, by modulating the extent of nitric oxide-modified proteins ( $S$-nitrosylation). The accumulation of $S$-nitrosylated proteins due to GSNOR downregulation is a feature of hepatocellular carcinoma, causing mitochondrial defects that sensitize these tumors to mitochondrial toxins, in particular to mitochondrial complex II inhibitor alpha-tocopheryl succinate ( $\alpha$ TOS). However, it is not known if mitophagy defects contribute to GSNOR-deficient cancer cells sensitivity to $\alpha$ TOS, nor if mitophagy inhibition could be used as a common mechanism to sensitize liver cancers to this toxin. Here, we provide evidence that GSNOR-deficient cancer cells show defective mitophagy. Furthermore, we show that $\alpha \mathrm{TOS}$ is a mitophagy inducer and that mitophagy defects of GSNOR-deficient liver cancer cells contribute to its toxicity. We finally prove that the inhibition of mitophagy by depletion of Parkin, a pivotal ubiquitin ligase targeting mitochondria for degradation, enhances $\alpha$ TOS toxicity, thus suggesting that this drug could be effective in treating mitophagy-defective tumors.

\section{Keywords}

Mitophagy, GSNOR, alpha-tocopheryl succinate, Parkin, S-nitrosylation, Hepatocellular carcinoma. 


\section{Introduction}

Mitophagy, the selective targeting of damaged mitochondria for lysosomal degradation, is an essential process controlling mitochondrial homeostasis. Being at the crossroads of metabolic, redox and cell death pathways, mitochondria play a central role in physiology and, not surprisingly, in several pathological settings, including cancer [1-3]. Although dysfunctional mitochondria are a feature of many malignancies, and contribute to the increased glycolytic metabolism referred as "Warburg effect" [4-6], it is becoming clear that these organelles may also contribute to tumorigenesis by i) producing signaling molecules [7-9]; ii) controlling $\mathrm{Ca}^{2+}$ homeostasis [10]; iii) acting as hub of cell death signals [11,12]; iv) catabolizing lipids and amino acids for energy production, or v) stimulating their de novo synthesis to generate biomass in proliferating cells $[13,14]$. Due to these multiple roles, changes in the mitochondrial mass, which mostly derives from an imbalance between biogenesis and mitophagy, has been linked to both tumorigenesis and cell survival, as well as to tumor suppression [15]. Although mitophagy appears to be defective during cancer initiation, it acts mainly as a cytoprotective mechanism during cancer progression, as it supports cell survival under stressful conditions, e.g. nutrient deprivation or hypoxia [1]. From a clinical point of view, such a cytoprotective role can contribute to chemoresistance [16-18]. In support to this, BCL2-interacting protein 3 like (NIX)-dependent mitophagy has been identified as a process attenuating doxorubicin toxicity in colorectal cancer [19]. Similarly, the upregulation of ariadne RBR E3 ubiquitin protein ligase $1(\mathrm{ARIH} 1)$ has been demonstrated to protect lung cancers from cisplatin by interacting with the mitochondrial potential sensor PTEN-induced kinase 1 (PINK1), and stimulating a Parkin-independent mitophagy [16]. 
Several studies tested mitophagy inhibition as a method to enhance drugs sensitivity $[20,21]$, and it has been suggested that selective silencing of mitophagy genes (e.g. PINK1 [16], Parkin [22,23], BCL2/adenovirus E1B 19 kDa protein-interacting protein 3, BNIP3 $[24,25]$ ), or the inhibition of lysosomes function (by chloroquine [26], or the alkaloid liensinine [27]) potentiates the antitumoral activity of conventional chemotherapeutics, e.g. doxorubicin [27], salinomycin [28], paclitaxel and vincristine [29]. Notwithstanding this amount of data, to date, the use of specific mitophagy inhibitors is still far from being implemented in combined anticancer therapies.

We have recently demonstrated that the denitrosylase $S$-nitrosoglutathione reductase (GSNOR) indirectly regulates a set of proteins - such as Parkin [30,31] - that are posttranslationally modified by nitric oxide (NO) through a reaction called $S$-nitrosylation [32,33]. Parkin S-nitrosylation inhibits its capability to target damaged mitochondria for mitophagy degradation [34,35]. As a result, cells in which GSNOR is downregulated are mitophagy-defective [30].

GSNOR is a highly conserved enzyme that has been found downregulated in human hepatocellular carcinomas [36,37] and breast cancer [38]. The etiological role of GSNOR in tumorigenesis is also confirmed by the evidence that GSNOR knock-out (KO) mice spontaneously develop liver cancer [36]. However, if this depends on mitophagy defects has not been investigated yet. In a previous work, we also demonstrated that GSNOR-KO cells show mitochondrial defects that can be exploited to selectively kill hepatocellular carcinoma cells [39] by the use of a class of mitochondrial drugs (named mitocans [40]) directed to the Complex II of the mitochondrial respiratory chain (also known as succinate dehydrogenase, SDH). 
Here we provide evidence that mitophagy is involved in the sensitivity of GSNOR-KO liver cancer cells to mitochondrial toxins, i.e. alpha-tocopheryl succinate ( $\alpha \mathrm{TOS})$ [41-43], suggesting the use of SDH-directed mitocans for the treatment of mitophagy-defective tumors.

\section{Materials and Methods}

\subsection{Cell culture and treatments}

HepG2 cell line was obtained from the Banca Biologica e Cell Factory (IRCCS AOU San Martino - IST Istituto Nazionale per la Ricerca sul Cancro). Huh-7 12 (HUH7) were purchased from Sigma-Aldrich. Both cell lines were grown in RPMI 1640 supplemented with $10 \%$ FBS and antibiotics at $37^{\circ} \mathrm{C}$ in an atmosphere of $5 \% \mathrm{CO}_{2}$. All cell lines were cultured for fewer than 2 months after resuscitation and were used from the third to the fifteenth passage in culture. Cell lines validation was carried out by the producer by means of DNA Profile STR (Short Tandem Repeat) and mycoplasma contamination was routinely screened by a PCR-based assay. All the cell culture media and supplements were purchased from Gibco, Thermo-Fisher Scientific.

Compounds and concentrations used in the study are as follows: carbonyl cyanide mchlorophenyl hydrazone (CCCP, Sigma-Aldrich), 2.5-10 $\mu \mathrm{M}$; chloroquine (CQ, SigmaAldrich), $20 \mu \mathrm{M}$; alpha-tocopheryl succinate ( $\alpha \mathrm{TOS}$, Sigma-Aldrich), 40-60 $\mu \mathrm{M}$. Incubation times are indicated in the figure legends.

\subsection{Gene silencing}

Transient knock down was performed by small interference RNA (siRNA) technique. Cell were transfected using RNAiMAX (Thermo Fisher Scientific) using endonuclease-prepared 
pools of siRNAs (esiRNA, Sigma-Aldrich) directed against GSNOR (siGSNOR) and Parkin (siParkin), or, as control, with a scramble siRNA duplex (siScr). HepG2 cells stably expressing eGFP-short-hairpin RNAs (shRNA) were generated in our lab with a procedure reported in [39].

\subsection{Analysis of cell viability and cell death.}

Dead cells were evaluated by Celigo Imaging Cytometer (Nexcelom Bioscience) upon staining with LIVE/DEAD ${ }^{\circledR}$ Cell Imaging Kit (488/570) (Thermo-Fisher Scientific). The percentage of dead cells was calculated as ratio between propidium iodide-stained cells (dead, red) and the sum of dead cells and calcein AM-positive cells (alive, green).

Cell viability was quantified by reading the fluorescence emission at $590 \mathrm{~nm}$ after $2 \mathrm{~h}$ incubation with AlamarBlue ${ }^{\circledR}$ Reagent (Thermo-Fisher Scientific) with a Victor X4 (PerkinElmer) plate reader.

Cell survival was assayed upon Cristal Violet staining. Briefly, cells were treated with 40 $\mu \mathrm{M} \alpha \mathrm{TOS}$ for $24 \mathrm{~h}$; then they were trypsinized and $1 / 5$ re-seeded in 6 -well plates in the presence or not of $40 \mu \mathrm{M} \alpha \mathrm{TOS}$ for 4 days. At the end of the treatment cells were washed twice with PBS, fixed and stained with a solution of $20 \%(\mathrm{v} / \mathrm{v})$ Methanol (WVR) and $0.05 \%$ $(w / v)$ Crystal violet (Sigma-Aldrich) on ice for 10 minutes. After washing, the plate was let completely dry at room temperature. Pictures were acquired with an Olympus microscope equipped with a $4 \mathrm{X}$ objective. For quantitation, Crystal violet was eluted with $100 \%$ methanol and absorbance measured at $595 \mathrm{~nm}$ by a Victor X4 plate reader.

\subsection{Analyses of mitochondrial mass and mitochondrial transmembrane potential $\left(\psi_{m}\right)$.}


Total mitochondrial mass and mitochondrial transmembrane potential $\left(\Delta \psi_{\mathrm{m}}\right)$ were analyzed by incubating cells with 50 nM MitoTracker Green-FM or 200 nM TMRM (Thermo-Fisher Scientific), respectively, for 30 minutes in serum-free DMEM. Stained cells were washed twice with cold PBS, collected and analyzed by flow cytometry (FACS Verse, BD-biosciences). Normalized $\Delta \psi_{\mathrm{m}}$ was calculated as TMRM/MitoTracker Green-FM relative fluorescence (geometric mean).

\subsection{Immunofluorescence microscopy and analyses.}

Cells were grown on cover slips preventively coated with Gelatin 1\% in PBS (Sigma Aldrich), treated as indicated, washed twice in cold PBS and fixed with 4\% paraformaldehyde (VWR) in PBS for 10 min at room temperature.

For mitochondrial dynamics analysis, cells were incubated with a permeabilization solution (PBS/Triton X-100 0.4\% v/v), blocked for $1 \mathrm{~h}$ with a blocking solution (PBS/normal goat serum $10 \% \mathrm{v} / \mathrm{v}$ ) and then incubated for $1 \mathrm{~h}$ with and anti-mitochondrial import receptor subunit TOM20 homolog (anti-TOM20 - sc-11415, Santa Cruz Biotechnology) antibody, or, alternatively, with an anti-heat shock protein A9 (anti-GRP75 - ADI-SPS-826, Enzo Life Sciences).

For the evaluation of mitophagy, cells were permeabilized in ice cold methanol (VWR) for 5 minutes, washed three times in PBS, incubated for $1 \mathrm{~h}$ in blocking solution and then over night with an anti-Microtubule-associated proteins 1A/1B light chain 3B (anti-LC3, 0231100, Nanotools) and anti-TOM20 (Santa Cruz Biotechnology) antibodies. Cells were then washed twice with PBS and incubated for $1 \mathrm{~h}$ with fluorophore-conjugated secondary antibodies (AlexaFluor 488 and 568). Nuclei were stained with $1 \square \mu \mathrm{g} / \mathrm{ml}$ Hoechst 33342 (Thermo-Fisher Scientific). Epifluorescence analysis was performed by using Delta Vision 
(Applied Precision) Olympus IX70 microscope. Confocal microscopy experiments were performed by using LSM800 microscope (ZEISS) equipped with an oil-immersion 63X objective and ZEN imaging software. Fluorescence images were adjusted for brightness, contrast and color balance by using Fiji [44] analysis software. Confocal microscopy images were deconvoluted using the software Huygens Professional (Scientific Volume Imaging).

3D-rendering of multi-stacks images was achieved by UCSF CHIMERA (Reagents of the University of California) [45]. Mitophagy rate was assessed upon incubation with $20 \mathrm{mM}$ chloroquine, added $2 \mathrm{~h}$ before the end of the treatments to block mitochondria degradation within the autophagosomes. The percentage of mitochondria particles colocalizing with LC3 puncta was calculated by Fiji analysis software using the open-source plugin ComDet v. 0.3.7. on at least 8 different cells/experimental condition. For both TOM20 and LC3 fluorescence channels, the parameters utilized were: Particle size $\geq 4 \mathrm{px}$; intensity threshold $=3$. The colocalization was considered positive if the maximum distance between the center of 2 particles was $\leq 4 \mathrm{px}$. The pictures showed represent 3Dprojections and were obtained by summing the fluorescence signal of the central z-Stacks (3 planes, $0.3 \mu \mathrm{m})$.

\subsection{Live-imaging confocal microscopy.}

Live-imaging monitoring of mitophagy was achieved by growing the cells on 96-well flatbottom plates for microscopy (Greiner). Cells were treated with $40 \mu \mathrm{M} \alpha \mathrm{TOS}$ where indicated for $24 \mathrm{~h}$. Cells were then stained for 30 minutes with 50 nM MitoTracker GreenFM, 200 nM LysoTracker Red (Thermo-Fisher Scientific) and 50 nM Nuclear Violet (Biomol). Then they were washes in PBS, replaced in cell medium and treated with $5 \mu \mathrm{M}$ 
CCCP or $40 \mu \mathrm{M} \alpha \mathrm{TOS}$ and placed in the incubator chamber of the ImageXpress Micro Confocal High-Content Imaging System (Molecular Devices) at $37^{\circ} \mathrm{C}$ in an atmosphere of $5 \% \mathrm{CO}_{2}$. Pictures were captured every 5 minutes for $60-90$ minutes.

\subsection{Transmission electron microscopy.}

HepG2 cells stably expressing an eGFP-short-hairpin against GSNOR or a scramble nontarget sequence, were treated with $40 \mu \mathrm{M} \alpha \mathrm{TOS}$ for $24 \mathrm{~h}$, then fixed with $2.5 \%$ glutaraldehyde (Sigma-Aldrich) buffered with $0.1 \mathrm{M}$ sodium phosphate, $\mathrm{pH}$ 7.4. Sections were prepared at the Core Facility for Integrated Microscopy (CFIM), Copenhagen University and images were acquired with a CM 100 BioTWIN electron microscope equipped with an Olympus Veleta digital camera. Figures were processed with an Olympus ITEM software.

\subsection{Protein determination.}

Protein concentration was determined by the method of Lowry [46].

\subsection{Western blot.}

Samples preparation and acquisition of Western blots were performed as previous reported [39]. Western blots shown are representative of at least $n=3$ independent experiments giving similar results. We used the following primary antibodies: antisuccinate dehydrogenase subunit A (anti-SDHA - ab14715, 1:5000) from Abcam; antiTOM20 (sc-11415, 1:5000), anti-nitric oxide synthase 2 (anti-NOS2 - sc-8310 1:1000), anti-GSNOR (sc-293460, 1:1000), anti-Parkin (sc-30130, 1:1000), anti-Voltage-dependent anion channel (anti-VDAC - sc-8828, 1 :2000) from Santa Cruz Biotechnology; anti-Vinculin 
(V4505, 1:10000) from Sigma-Aldrich; anti-thioredoxin 1 (anti-Trx1 - 2298, 1:1000) from Cell Signaling.

\subsection{Statistical analyses.}

Values are expressed as means \pm SD (or SEM where specified) and statistical significance was assessed by Student's t-test using Prism 8.0 (GraphPad Software, Inc.) in order to determine which groups were significantly different from the others.

\section{Results}

\subsection{GSNOR-deficient hepatocellular carcinoma cells show defective mitochondrial} dynamics.

In order to study the effects of GSNOR-ablation on mitochondria in hepatocellular carcinoma, we took advantage of two different hepatoma cell lines: HUH7, in which we transiently knocked-down GSNOR by RNA interference, and HepG2, stably expressing eGFP-shRNAs targeting GSNOR (shGSNOR), or a non-target sequence (shScr) as a control. As shown in Figure 1A, neither transient nor stable GSNOR ablation affected the expression levels of nitric oxide synthase 2 (NOS) - the predominant NO-producing enzyme in HUH7 and HepG2 cells - and thioredoxin 1 (Trx1), which might complement lack of GSNOR denitrosylating activity induced by sh or siRNAs. These data suggest that no compensatory mechanisms are induced by GSNOR downregulation in our experimental conditions. However, as previously reported in murine neurons and fibroblasts [30,31], GSNOR knocking-down resulted in a marked decrease of mitochondrial transmembrane potential $\left(\psi_{\mathrm{m}}\right)$ (Figure 1B) and a fragmentation of mitochondrial network 
(Figures 1C and D). Overall, these data suggest that, in hepatocellular carcinoma cells, GSNOR deficiency results in mitochondrial fragmentation and depolarization.

\subsection{GSNOR-deficient hepatocellular carcinoma cells show defective mitophagy.}

We next investigated the effects of GSNOR downregulation on mitophagy, since this is a mechanism deeply impaired in condition of nitrosative stress induced by GSNOR decrease [30]. To this end, we treated HUH7 cells with the uncoupling agent CCCP, a well-known mitophagy inducer and evaluated mitochondrial mass upon MitoTracker Green staining as indirect measure of mitophagy. (Figure 2A). Cytofluorometric assay indicated that CCCP induced a milder decrement of mitochondrial mass in siGSNOR than the control (siScr) counterpart, suggesting that mitochondrial removal was less efficient. To confirm these set of data, we performed live-imaging confocal microscopy analyses of $\mathrm{HUH7}$ cells stained with Lysoracker Red (to follow lysosomes) and MitoTracker Green (to identify mitochondria). Results shown in Figure 2B (Movies 1-6) indicate that GSNOR-deficiency induced a defective recognition of mitochondria, strengthening the idea that mitophagy rate was compromised in siGSNOR cells. Accordingly, Western Blot analyses performed on HepG2 cells showed that the levels of three mitochondrial proteins commonly used as an estimation of mitochondrial mass (i.e. SDHA, VDAC and TOM20) were only slightly affected by CCCP in GSNOR-deficient conditions (shGSNOR) if compared with those measured in control counterparts (shScr) (Figure 2C). Overall, these results suggest that loss of GSNOR impairs mitophagy in hepatocellular carcinoma cells.

3.3. GSNOR-deficient hepatocellular carcinoma cells are insensitive to $\alpha$ TOS-induced mitophagy. 
We previously demonstrated that, in hepatoma cells, GSNOR-deficiency is a condition associated with a rearrangement of the respiratory chain, namely the upregulation of complex II (succinate dehydrogenase, SDH) activity and oxygen consumption [39], presumably as a mechanism to compensate the inhibition of complex I and IV. This feature provided the molecular rationale to the use of SDH-targeting mitochondrial toxins, exemplified by the vitamin E-derivative $\alpha$ TOS that, indeed, showed high (and selective) toxicity towards GSNOR-depleted cells [39].

In the light of the results so far obtained, we wondered if $\alpha$ TOS was able to induce mitophagy and, further, if defects in mitophagy observed in GSNOR-deficient cells could contribute to their enhanced sensitivity towards this drug. To this end, we performed electron microscopy analyses of HepG2 cells treated with $\alpha$ TOS for $24 \mathrm{~h}$ and observed that mitochondrial ultrastructure was compromised. In particular, we noticed a decrease in the average mitochondrial size and in the number of mitochondrial cristae (Figure 3 ) in both shScr and shGSNOR cells. Interestingly, in shScr cells we noticed the presence of double-membraned structures surrounding the damaged organelles, presumably early autophagosomes. On the contrary, these structures were absent (or very rare) in GSNORdeficient cells treated with $\alpha$ TOS, notwithstanding mitochondria shape appeared severely compromised already in control (vehicle-treated) conditions. In order to confirm these results, we performed immunofluorescence analysis by labeling mitochondria with an antiTOM20 antibody, and autophagosomes with an anti-LC3 antibody. To highlight mitophagy rate, this experiment was performed in the presence of chloroquine (CQ), a well-known inhibitor of lysosome acidification that blocks the degradation of autophagolysosomes content [47]. Fluorescence microscopy analyses indicated that $\alpha$ TOS was able to target mitochondria toward lysosomal degradation in siScr HUH7 cells, but not in GSNOR- 
deficient cells (Figure 4A). Interestingly, the inability to trigger mitophagy was comparable to that observed in cells downregulating Parkin (siParkin) - the ubiquitin-ligase involved in targeting damaged mitochondria for degradation through mitophagy - that were selected as control (Figure 4A). An estimation of mitophagy rate that gives the general idea of this phenomenon was provided in Figure 4B as unbiased count of the colocalization between anti-TOM20/anti-LC3 double positive particles. In line with these observations, we obtained similar results in HUH7 cells analyzed by live-imaging confocal microscopy, with aTOS treatment triggering mitophagy in siScr but not in siGSNOR cells (Figure $4 \mathbf{C}$, Movies 7-12). Flow cytometry analyses were perfomed to quantify the decrease of mitochondrial mass, eventually confirming that siGSNOR cells retained more mitochondria upon $\alpha$ TOS treatment than the siScr counterpart (Figure 4D), providing additional evidence that GSNOR-deficient cells were unable to remove $\alpha$ TOS-damaged mitochondria through selective autophagy.

\subsection{Mitophagy impairment contributes to $\alpha$ TOS cytotoxicity.}

We finally investigated the relationship between mitophagy and $\alpha$ TOS toxicity by analyzing cell death and survival upon GSNOR and/or Parkin downregulation (Figure 5A) in hepatocellular carcinoma cells. To this end, we treated HUH7 cells with $\alpha$ TOS for $24 \mathrm{~h}$ and evaluated cell death by combined staining with green-fluorescent calcein-AM (for living cells) and propidium iodide (for dead cells). Fluorescence microscopy analyses showed that GSNOR-deficient cells were more sensitive to $\alpha$ TOS cytotoxicity, confirming data previously obtained in our laboratory [39] (Figure 5B, C). Interestingly, we also observed that Parkin downregulation enhanced $\alpha$ TOS-induced cell death in siScr cell, whereas it did not produce any additional effect in siGSNOR cells, arguing for a S-nitrosylation and 
Parkin laying on the same pathways. We then repeated the same experiment in HepG2 cells (Figure 5D), confirming the same role of $\alpha$ TOS on cell viability in shGSNOR cells, where no further effects were observed in combination with siParkin (Figure 5E). This data suggested that, by sensitizing shScr cells to $\alpha$ TOS, Parkin silencing abolished the differences between GSNOR-deficient and proficient cells (Figure 5E). We finally confirmed these results by Cristal Violet survival assay of cells treated for 4 days with $\alpha$ TOS. GSNOR downregulation as well as Parkin silencing resulted in a lower survival rate if compared with GSNOR- or Parkin-proficient (shScr or siScr) counterparts (Figure 5F). In conclusion, these experiments reveal that it is possible to sensitize hepatocellular carcinoma cells to $\alpha$ TOS by inhibiting mitophagy. Moreover, our data suggest that $S$ nitrosylation contributes to cell susceptibility to $\alpha \mathrm{TOS}$ by a mitophagy-dependent mechanism, inasmuch Parkin does not, as these cells are already mitophagy defective (Figure 6).

\section{Discussion}

Mechanisms underlying mitophagy are currently under intense investigation as they represent potential therapeutic targets due to the cytoprotective role of this process in cancer. In this regard, it has been demonstrated that the efficiency in clearing up drugdamaged mitochondria attenuates, or even abolishes, treatment effectiveness in several chemotherapy settings $[17,20,48]$. Starting from this evidence, many research groups developed the idea of using mitophagy inhibitors to enhance the efficacy of conventional chemotherapies [21]. Similarly, the identification of mitophagy-defective cancer subtypes advocates the application of mitochondrial-targeting therapies designed to selectively affect cancer cells survival, avoiding mitophagy-proficient cells [21]. Interestingly, the main 
characterized mitophagy regulators, i.e. the PINK1/Parkin system, BNIP3 and NIX, have been shown to be downregulated in several cancer types [16,25,49-52], suggesting that these could be targets of mitochondrial-directed therapies.

It is commonly known that Parkin-null mice develop liver cancer spontaneously [51]. Intriguingly, mice deficient for the denitrosylase GSNOR develop liver cancer as well [36,53], this pointing toward a common mechanism underlying tumorigenesis [54]. As a matter of fact, GSNOR-deficient cells show aberrant $S$-nitrosylation of Parkin, condition that compromises the E3-Ub ligase activity [34] and results in mitophagy defects [30]. Supported by the findings of this work, it is reasonable to include GSNOR-deficient hepatocellular carcinoma among the mitophagy-defective cancers.

In addition, we recently demonstrated that, due to mitochondrial electron transport chain rearrangements, GSNOR-deficient liver cancers cells are particularly susceptible to the mitochondrial complex II-targeting drug $\alpha$ TOS $[39,41,55]$. We here expanded the knowledge about the mechanism of action of $\alpha \mathrm{TOS}$, demonstrating for the first time that this toxin induces mitophagy, and that, similarly to other chemotherapics, the removal of damaged mitochondria through mitophagy dampens its toxicity. These discoveries are in line with previous data indicating lysosome instability at the bases of $\alpha$ TOS-induced apoptosis [56] in solid tumors, in particular colorectal [56] and breast $[57,58]$ cancer. It is worth to note that breast cancer is actually characterized by GSNOR downregulation [38]. However, whether mitophagy defects contribute to $\alpha$ TOS efficacy in breast cancer eradication still needs to be elucidated. More generally, the effectiveness of mitocans in the treatment of mitophagy-defective tumors is still neglected, even though it might represent an intriguing field of investigation. 
In conclusion, in the present study, we propose the use of $\alpha$ TOS as a promising tool toward GSNOR- and Parkin-defective, as well as other mitophagy-deficient tumors, and provide a molecular rationale to predict tumor response to mitocans.

\section{Acknowledgements}

We would like to thank Laila Fisher for secretary assistance and Vanda Turcanova for the technical support. This work has been supported by Danish Cancer Society Grant Kræftens Bekæmpelses Videnskabelige Udvalg (KBVU) Grant [R146-A9414 and R231A13855 to G. F, and R204-A12424 to D.D.Z.], Novo Nordisk Foundation (2018-0052550 to G.F), Associazione Italiana per la Ricerca sul Cancro (AIRC) Grant [IG20719] (to G.F.), LEO foundation (LF-OC-19-000004 to D.D.Z.), the Melanoma Research Alliance (to D.D.Z.). The laboratories in Copenhagen is part of the Center of Excellence in Autophagy, Recycling and Disease (CARD), funded by the Danish National Research Foundation (DNRF125).

Author contributions: S.R. conceived and designed the study, performed the majority of experiments and interpreted the data; L.D.L. contributed to cell maintenance, treatments and performed survival assays; S.M. performed flow cytometry analyses; D.D.Z. and G.F. critically commented the manuscript and the figures; S.R. and G.F. wrote the manuscript. Conflicts of Interest: The authors state that no conflict of interests does exist. 


\section{References}

[1] J.Y. Chang, H.S. Yi, H.W. Kim, M. Shong, Dysregulation of mitophagy in carcinogenesis and tumor progression, Biochim. Biophys. Acta - Bioenerg. 1858 (2017) 633-640. doi:10.1016/j.bbabio.2016.12.008.

[2] S. Vyas, E. Zaganjor, M.C. Haigis, Mitochondria and Cancer, Cell. 166 (2016) 555-566. doi:10.1016/j.cell.2016.07.002.

[3] D.C. Chan, Mitochondria: Dynamic Organelles in Disease, Aging, and Development, Cell. 125 (2006) 1241-1252. doi:10.1016/j.cell.2006.06.010.

[4] M. V Liberti, J.W. Locasale, The Warburg Effect: How Does it Benefit Cancer Cells?, Trends Biochem. Sci. 41 (2016) 211-218. doi:10.1016/j.tibs.2015.12.001.

[5] J. Lu, M. Tan, Q. Cai, The Warburg effect in tumor progression: Mitochondrial oxidative metabolism as an anti-metastasis mechanism, Cancer Lett. 356 (2015) 156-164. doi:10.1016/j.canlet.2014.04.001.

[6] M.G. Vander Heiden, L.C. Cantley, C.B. Thompson, Understanding the Warburg effect: the metabolic requirements of cell proliferation., Science. 324 (2009) 1029-33. doi:10.1126/science.1160809.

[7] L. Tochhawng, S. Deng, S. Pervaiz, C.T. Yap, Redox regulation of cancer cell migration and invasion, Mitochondrion. 13 (2013) 246-253. doi:10.1016/j.mito.2012.08.002.

[8] M.C. De Santis, P.E. Porporato, M. Martini, A. Morandi, Signaling Pathways Regulating Redox Balance in Cancer Metabolism, Front. Oncol. 8 (2018) 126. doi:10.3389/fonc.2018.00126.

[9] A. Rasola, L. Neckers, D. Picard, Mitochondrial oxidative phosphorylation TRAP(1)ped in tumor cells, Trends Cell Biol. 24 (2014) 455-463. doi:10.1016/j.tcb.2014.03.005.

[10] C.R. Reczek, N.S. Chandel, ROS Promotes Cancer Cell Survival through Calcium Signaling, Cancer Cell. 33 (2018) 949-951. doi:10.1016/j.ccell.2018.05.010.

[11] D.R. Green, L. Galluzzi, G. Kroemer, Metabolic control of cell death, Science (80-. ). 345 (2014) 1250256-1250256. doi:10.1126/science.1250256.

[12] A. Kasahara, L. Scorrano, Mitochondria: from cell death executioners to regulators of cell differentiation, Trends Cell Biol. 24 (2014) 761-770. doi:10.1016/j.tcb.2014.08.005.

[13] R.J. De Berardinis, N.S. Chandel, Fundamentals of cancer metabolism, Sci. Adv. 2 (2016) 107-111. doi:10.1126/sciadv.1600200. 
[14] T. Han, D. Kang, D. Ji, X. Wang, W. Zhan, M. Fu, H.B. Xin, J. Bin Wang, How does cancer cell metabolism affect tumor migration and invasion?, Cell Adhes. Migr. 7 (2013) 395-403. doi:10.4161/cam.26345.

[15] J.Y. Chang, H.-S. Yi, H.-W. Kim, M. Shong, Dysregulation of mitophagy in carcinogenesis and tumor progression, Biochim. Biophys. Acta - Bioenerg. 1858 (2017) 633-640. doi:10.1016/j.bbabio.2016.12.008.

[16] E. Villa, E. Proïcs, C. Rubio-Patiño, S. Obba, B. Zunino, J.P. Bossowski, R.M. Rozier, J. Chiche, L. Mondragón, J.S. Riley, S. Marchetti, E. Verhoeyen, S.W.G. Tait, J.E. Ricci, Parkin-Independent Mitophagy Controls Chemotherapeutic Response in Cancer Cells, Cell Rep. 20 (2017) 2846-2859. doi:10.1016/j.celrep.2017.08.087.

[17] L. Hardy, M. Frison, M. Campanella, Breast cancer cells exploit mitophagy to exert therapy resistance, Oncotarget. 9 (2018) 14040-14041. doi:10.18632/oncotarget.24533.

[18] M. Vara-Perez, B. Felipe-Abrio, P. Agostinis, Mitophagy in Cancer: A Tale of Adaptation, Cells. 8 (2019) 493. doi:10.3390/cells8050493.

[19] C. Yan, L. Luo, C.-Y. Guo, S. Goto, Y. Urata, J.-H. Shao, T.-S. Li, Doxorubicin-induced mitophagy contributes to drug resistance in cancer stem cells from HCT8 human colorectal cancer cells, Cancer Lett. 388 (2017) 34-42. doi:10.1016/j.canlet.2016.11.018.

[20] P. Bhat, J. Kriel, B. Shubha Priya, Basappa, N.S. Shivananju, B. Loos, Modulating autophagy in cancer therapy: Advancements and challenges for cancer cell death sensitization, Biochem. Pharmacol. 147 (2018) 170-182. doi:10.1016/j.bcp.2017.11.021.

[21] H.Y. Chiu, E.X.Y. Tay, D.S.T. Ong, R. Taneja, Mitochondrial dysfunction at the centre of cancer therapy, Antioxid. Redox Signal. 00 (2019) 1-22. doi:10.1089/ars.2019.7898.

[22] C. Zhao, R. He, M. Shen, F. Zhu, M. Wang, Y. Liu, H. Chen, X. Li, R. Qin, PINK1/Parkin-Mediated Mitophagy Regulation by Reactive Oxygen Species Alleviates Rocaglamide A-Induced Apoptosis in Pancreatic Cancer Cells, Front. Pharmacol. 10 (2019) 1-13. doi:10.3389/fphar.2019.00968.

[23] L. Song, Y. Huang, X. Hou, Y. Yang, S. Kala, Z. Qiu, R. Zhang, L. Sun, PINK1/Parkin-Mediated Mitophagy Promotes Resistance to Sonodynamic Therapy, Cell. Physiol. Biochem. 49 (2018) 18251839. doi:10.1159/000493629.

[24] J. Okami, D.M. Simeone, C.D. Logsdon, Silencing of the Hypoxia-Inducible Cell Death Protein BNIP3 
in Pancreatic Cancer, Cancer Res. 64 (2004) 5338 LP - 5346. doi:10.1158/0008-5472.CAN-04-0089.

[25] A.H. Chourasia, K.F. Macleod, Tumor suppressor functions of BNIP3 and mitophagy, Autophagy. 11 (2015) 1937-1938. doi:10.1080/15548627.2015.1085136.

[26] T. Kimura, Y. Takabatake, A. Takahashi, Y. Isaka, Chloroquine in Cancer Therapy: A Double-Edged Sword of Autophagy, Cancer Res. 73 (2013) 3 LP - 7. doi:10.1158/0008-5472.CAN-12-2464.

[27] J. Zhou, G. Li, Y. Zheng, H.M. Shen, X. Hu, Q.L. Ming, C. Huang, P. Li, N. Gao, A novel autophagy/mitophagy inhibitor liensinine sensitizes breast cancer cells to chemotherapy through DNM1L-mediated mitochondrial fission, Autophagy. 11 (2015) 1259-1279. doi:10.1080/15548627.2015.1056970.

[28] A. Managò, L. Leanza, L. Carraretto, N. Sassi, S. Grancara, R. Quintana-Cabrera, V. Trimarco, A. Toninello, L. Scorrano, L. Trentin, G. Semenzato, E. Gulbins, M. Zoratti, I. Szabò, Early effects of the antineoplastic agent salinomycin on mitochondrial function, Cell Death Dis. 6 (2015). doi:10.1038/cddis.2015.263.

[29] C. Yan, T.S. Li, Dual role of mitophagy in cancer drug resistance, Anticancer Res. 38 (2018) 617621. doi:10.21873/anticanres.12266.

[30] S. Rizza, S. Cardaci, C. Montagna, G. Di Giacomo, D. De Zio, M. Bordi, E. Maiani, S. Campello, A. Borreca, A.A. Puca, J.S. Stamler, F. Cecconi, G. Filomeni, S -nitrosylation drives cell senescence and aging in mammals by controlling mitochondrial dynamics and mitophagy, Proc. Natl. Acad. Sci. U. S. A. 10 (2018) E3388-E3397. doi:10.1007/s10986-018-9401-8.

[31] S. Rizza, G. Filomeni, Denitrosylate and live longer: how ADH5/GSNOR links mitophagy to aging, Autophagy. 14 (2018) 1285-1287. doi:10.1080/15548627.2018.1475818.

[32] D.T. Hess, A. Matsumoto, S.-O.O. Kim, H.E. Marshall, J.S. Stamler, Protein S-nitrosylation: purview and parameters, Nat.Rev.Mol.Cell Biol. 6 (2005) 150-166. doi:10.1038/nrm1569.

[33] D.T. Hess, J.S. Stamler, Regulation by S-nitrosylation of protein post-translational modification, J. Biol. Chem. 287 (2012) 4411-4418. doi:10.1074/jbc.R111.285742.

[34] K.K.K. Chung, B. Thomas, X. Li, O. Pletnikova, J.C. Troncoso, L. Marsh, V.L. Dawson, T.M. Dawson, S-nitrosylation of parkin regulates ubiquitination and compromises parkin's protective function., Science (80-. ). 304 (2004) 1328-31. doi:10.1126/science.1093891.

[35] T. Nakamura, S.A. Lipton, S-Nitrosylation of Critical Protein Thiols Mediates Protein Misfolding and 
Mitochondrial Dysfunction in Neurodegenerative Diseases, Antioxid. Redox Signal. 14 (2010) 14791492. doi:10.1089/ars.2010.3570.

[36] W. Wei, B. Li, M.A. Hanes, S. Kakar, X. Chen, L. Liu, S-nitrosylation from GSNOR deficiency impairs DNA repair and promotes hepatocarcinogenesis., Sci. Transl. Med. 2 (2010) 19 ra13. doi:10.1126/scitransImed.3000328.

[37] C.H. Tang, W. Wei, M.A. Hanes, L. Liu, Hepatocarcinogenesis driven by GSNOR deficiency is prevented by iNOS inhibition, Cancer Res. 73 (2013) 2897-2904. doi:10.1158/0008-5472.CAN-123980.

[38] A. Cañas, L.M. López-Sánchez, J. Peñarando, A. Valverde, F. Conde, V. Hernández, E. Fuentes, C. López-Pedrera, J.R. de la Haba-Rodríguez, E. Aranda, A. Rodríguez-Ariza, Altered S-nitrosothiol homeostasis provides a survival advantage to breast cancer cells in HER2 tumors and reduces their sensitivity to trastuzumab, Biochim. Biophys. Acta - Mol. Basis Dis. 1862 (2016) 601-610. doi:10.1016/j.bbadis.2016.02.005.

[39] S. Rizza, C. Montagna, S. Cardaci, E. Maiani, G. Di Giacomo, V. Sanchez-Quiles, B. Blagoev, A. Rasola, D. De Zio, J.S. Stamler, F. Cecconi, G. Filomeni, S-nitrosylation of the mitochondrial chaperone TRAP1 sensitizes hepatocellular carcinoma cells to inhibitors of succinate dehydrogenase, Cancer Res. 76 (2016) 4170-4182. doi:10.1158/0008-5472.CAN-15-2637.

[40] J. Neuzil, L.-F. Dong, J. Rohlena, J. Truksa, S.J. Ralph, Classification of mitocans, anti-cancer drugs acting on mitochondria, Mitochondrion. 13 (2013) 199-208. doi:10.1016/j.mito.2012.07.112.

[41] L.-F. Dong, P. Low, J.C. Dyason, X.-F. Wang, L. Prochazka, P.K. Witting, R. Freeman, E. Swettenham, K. Valis, J. Liu, R. Zobalova, J. Turanek, D.R. Spitz, F.E. Domann, I.E. Scheffler, S.J. Ralph, J. Neuzil, Alpha-tocopheryl succinate induces apoptosis by targeting ubiquinone-binding sites in mitochondrial respiratory complex II., Oncogene. 27 (2008) 4324-35. doi:10.1038/onc.2008.69.

[42] J. Neuzil, Vitamin E succinate and cancer treatment: a vitamin E prototype for selective antitumour activity., Br. J. Cancer. 89 (2003) 1822-6. doi:10.1038/sj.bjc.6601360.

[43] J. Neuzil, T. Weber, N. Gellert, C. Weber, Selective cancer cell killing by alpha-tocopheryl succinate., Br. J. Cancer. 84 (2001) 87-89. doi:10.1054/bjoc.2000.1559.

[44] J. Schindelin, I. Arganda-Carreras, E. Frise, V. Kaynig, M. Longair, T. Pietzsch, S. Preibisch, C. Rueden, S. Saalfeld, B. Schmid, J.Y. Tinevez, D.J. White, V. Hartenstein, K. Eliceiri, P. Tomancak, A. 
Cardona, Fiji: An open-source platform for biological-image analysis, Nat. Methods. 9 (2012) 676682. doi:10.1038/nmeth.2019.

[45] E.F. Pettersen, T.D. Goddard, C.C. Huang, G.S. Couch, D.M. Greenblatt, E.C. Meng, T.E. Ferrin, UCSF Chimera—A visualization system for exploratory research and analysis, J. Comput. Chem. 25 (2004) 1605-1612. doi:10.1002/jcc.20084.

[46] O.H. Lowry, N.J. Rosebrough, A.L. Farr, R.J. Randall, PROTEIN MEASUREMENT WITH THE FOLIN PHENOL REAGENT, J. Biol. Chem. . 193 (1951) 265-275.

http://www.jbc.org/content/193/1/265.short.

[47] M. Mauthe, I. Orhon, C. Rocchi, X. Zhou, M. Luhr, K.-J. Hijlkema, R.P. Coppes, N. Engedal, M. Mari, F. Reggiori, Chloroquine inhibits autophagic flux by decreasing autophagosome-lysosome fusion, Autophagy. 14 (2018) 1435-1455. doi:10.1080/15548627.2018.1474314.

[48] S.-F. Wang, M.-S. Chen, Y.-C. Chou, Y.-F. Ueng, P.-H. Yin, T.-S. Yeh, H.-C. Lee, Mitochondrial dysfunction enhances cisplatin resistance in human gastric cancer cells via the ROS-activated GCN2-elF2a-ATF4-xCT pathway, Oncotarget. 7 (2016). doi:10.18632/oncotarget.12356.

[49] E. Villa, E. Proïcs, C. Rubio-Patiño, S. Obba, B. Zunino, J.P. Bossowski, R.M. Rozier, J. Chiche, L. Mondragón, J.S. Riley, S. Marchetti, E. Verhoeyen, S.W.G. Tait, J.-E. Ricci, Parkin-Independent Mitophagy Controls Chemotherapeutic Response in Cancer Cells, Cell Rep. 20 (2017) 2846-2859. doi:10.1016/j.celrep.2017.08.087.

[50] N. Yao, C. Wang, N. Hu, Y. Li, M. Liu, Y. Lei, M. Chen, L. Chen, C. Chen, P. Lan, W. Chen, Z. Chen, D. Fu, W. Ye, D. Zhang, Inhibition of PINK1/Parkin-dependent mitophagy sensitizes multidrugresistant cancer cells to B5G1, a new betulinic acid analog, Cell Death Dis. 10 (2019) 232. doi:10.1038/s41419-019-1470-z.

[51] J.P. Bernardini, M. Lazarou, G. Dewson, Parkin and mitophagy in cancer, Oncogene. 36 (2016) 1315. doi:10.1038/onc.2016.302.

[52] J. Zhang, P.A. Ney, Role of BNIP3 and NIX in cell death, autophagy, and mitophagy, Cell Death Differ. 16 (2009) 939. doi:0.1038/cdd.2009.16.

[53] W. Wei, Z. Yang, C.H. Tang, L. Liu, Targeted deletion of GSNOR in hepatocytes of mice causes nitrosative inactivation of O6-alkylguanine-dna alkyltransferase and increased sensitivity to genotoxic diethylnitrosamine, Carcinogenesis. 32 (2011) 973-977. doi:10.1093/carcin/bgr041. 
[54] S. Rizza, G. Filomeni, Tumor Suppressor Roles of the Denitrosylase GSNOR, Crit. Rev. Oncog. 21 (2016) 433-445. doi:10.1615/CritRevOncog.2017021074.

[55] L.F. Dong, V.J.A. Jameson, D. Tilly, J. Cerny, E. Mahdavian, A. Marín-Hernández, L. HernándezEsquivel, S. Rodríguez-Enríquez, J. Stursa, P.K. Witting, B. Stantic, J. Rohlena, J. Truksa, K. Kluckova, J.C. Dyason, M. Ledvina, B.A. Salvatore, R. Moreno-Sánchez, M.J. Coster, S.J. Ralph, R.A.J. Smith, J. Neuzil, Mitochondrial targeting of vitamin E succinate enhances its pro-apoptotic and anti-cancer activity via mitochondrial complex II, J. Biol. Chem. 286 (2011) 3717-3728. doi:10.1074/jbc.M110.186643.

[56] J. Neuzil, M. Zhao, G. Ostermann, M. Sticha, N. Gellert, C. Weber, J.W. Eaton, U.T. Brunk, Alphatocopheryl succinate, an agent with in vivo anti-tumour activity, induces apoptosis by causing Iysosomal instability, Biochem. J. 362 (2002) 709-715. doi:10.1042/0264-6021:3620709.

[57] M.P. Malafa, L.T. Neitzel, Vitamin E Succinate Promotes Breast Cancer Tumor Dormancy, J. Surg. Res. 93 (2000) 163-170. doi:10.1006/jsre.2000.5948.

[58] L.F. Dong, R. Freeman, J. Liu, R. Zobaiova, A. Marin-Hernandez, M. Stantic, J. Rohlena, K. Valis, S. Rodriguez-Enriquez, B. Butcher, J. Goodwin, U.T. Brunk, P.K. Witting, R. Moreno-Sanchez, I.E. Scheffler, S.J. Raiph, J. Neuzil, Suppression of tumor growth in vivo by the mitocan a-tocopheryl succinate requires respiratory complex II, Clin. Cancer Res. 15 (2009) 1593-1600. doi:10.1158/10780432.CCR-08-2439. 


\section{Figure Legends}

Figure 1. GSNOR-deficient hepatocellular carcinoma cells show defective mitochondria. (A) Western blot analysis of NOS2, Trx1 and GSNOR in HUH7 cells transiently downregulating GSNOR (siGSNOR) and HepG2 cells stably expressing eGFPshRNAs against GSNOR (shGSNOR), along with their relative scrambled RNA-trasfected counterparts (siScr, shScr respectively). Vinculin was selected as loading control. (B) Mitochondrial transmembrane potential $\left(\Delta \psi_{\mathrm{m}}\right)$ in $\mathrm{HUH} 7$ and HepG2 cells evaluated by flow cytometric analysis of TMRM fluorescence. Values are normalized on the total mitochondrial mass (MitoTracker Green relative fluorescence intensity) and expressed as fold change. Values represent the means $\pm S D$ of $n=3$ independent experiments. * $p<$ $0.05 ;{ }^{* *} p<0.01$. (C) $3 \mathrm{D}$ reconstruction of mitochondrial network in siScr and siGSNOR HUH7 cells revealed by confocal fluorescence microscopy upon incubation with an antibody against the mitochondrial protein TOM20 (red). 3D-rendering of TOM20 signal is shown on the right panels and represents 4-6 z-stacks $(0.3 \mu \mathrm{m}$ size $)$. Hoechst 33342 (blue) was used to visualize nuclei. Scale bar $10 \mu \mathrm{m}$. (D) Representative fluorescence microscopy analyses of mitochondrial networks of shScr and shGSNOR HepG2 cells performed upon incubation with an antibody against Grp75. Scale bar $20 \mu \mathrm{m}$.

\section{Figure 2. GSNOR-deficient hepatocellular carcinoma cells show defective}

mitophagy. (A) Mitochondrial mass analyzed by flow cytofluorometric detection of MitoTracker Green fluorescence of siScr and siGSNOR HUH7 cells treated for $4 \mathrm{~h}$ with 2.5 or $5 \mu \mathrm{M} \mathrm{CCCP.} \mathrm{Cytofluorometric} \mathrm{histograms} \mathrm{are} \mathrm{shown} \mathrm{on} \mathrm{the} \mathrm{left.} \mathrm{Values} \mathrm{(on} \mathrm{the} \mathrm{right)}$ represent the means \pm SEM of $n=3$ independent experiments performed in triplicate. ${ }^{* *} p$ $<0.01$. (B) Representative frames (at 0', 15' and 30') captured upon live-imaging 
fluorescence microscopy (Movies 1-6) of siScr and siGSNOR HUH7 stained with LysoTracker Red (red), MitoTracker Green (green) and Nuclear Violet (blue) to visualize lysosomes, mitochondria and nuclei, respectively. $5 \mu \mathrm{M}$ CCCP (or DMSO as vehicle) was added before images acquisition to induce mitophagy. Images were acquired every 5 minutes for 1 h. (C) Western blot analysis of succinate dehydrogenase subunit A (SDHA), Voltage-dependent anion channel (VDAC) and Mitochondrial import receptor subunit TOM20 homolog (TOM20) performed on shScr and shGSNOR HepG2 upon treatment with $10 \mu \mathrm{M}$ CCCP (or DMSO) for $3 \mathrm{~h}$. Vinculin was used as loading control. CCCP/DMSO protein ratio - normalized on Vinculin - is shown below the immuno-reactive bands and indicates the fold decrease of each mitochondrial protein upon CCCP treatment.

Figure 3. $\alpha$ TOS alters mitochondria structure and induces autophagosome formation. Transmission electron microscopy images of shScr and shGSNOR HepG2 treated for $24 \mathrm{~h}$ with $40 \mu \mathrm{M} \alpha \mathrm{TOS}$ or vehicle (DMSO). Magnification of selected fields (yellow dotted squares) are shown on the right panels. Mitochondria are highlighted in light brown and double-membraned structures are highlighted in light blue. Scale bar $5 \mu \mathrm{m}$

Figure 4. GSNOR-deficient hepatocellular carcinoma cells are insensitive to $\alpha$ TOSinduced mitophagy. (A) Mitophagy evaluation by fluorescence confocal microscopy of siScr, siGSNOR and siParkin HUH7 cells treated for $24 \mathrm{~h}$ with $40 \mu \mathrm{M} \alpha \mathrm{TOS}$ and incubated with chloroquine (CQ) for $4 \mathrm{~h}$ to block mitochondrial degradation within autophagolysosomes. Mitochondria were labeled with an antibody against TOM20 (red), whereas autophagosomes were detected by using an anti-LC3 antibody (green). Hoechst 33342 (blue) was used to visualize nuclei. 3 central z-stacks $(0.3 \mu \mathrm{m}$ size) were merged in 
the microscopy pictures while $>6$ stacks were used for the 3D-rendering of TOM20 and LC3 signals (right panels). (B) Number of mitochondria colocalizing with LC3-positive puncta in $\mathrm{CQ} \pm \alpha$ TOS-treated cells calculated by Fiji analysis software using the opensource plugin ComDet v. $0.3 .7 .{ }^{*} p<0.05 ;{ }^{* *} p<0.001$; ns $=$ not significant. At least 8 cells/experimental condition were counted. (C) Representative frames captured upon liveimaging fluorescence microscopy (Movies 7-12) of siScr and siGSNOR HUH7 stained with LysoTracker Red (red), MitoTracker Green (green) and Nuclear Violet (blue) to visualize lysosomes, mitochondria and nuclei, respectively. Cells, where indicated, were pre-treated for $24 \mathrm{~h}$ with $40 \mu \mathrm{M} \alpha \mathrm{TOS}$ (or DMSO). After the staining, $\alpha$ TOS (or DMSO) was added before images acquisition. Images were acquired every 5 minutes for 90 minutes. (D) Mitochondrial mass analyzed by flow cytoflurometric detection of MitoTracker Green fluorescence of siScr and siGSNOR HUH7 cells treated for $24 \mathrm{~h}$ with $60 \mu \mathrm{M} \alpha \mathrm{TOS}$. Values represent the means $\pm S D$ of $n=3$ independent experiments. ${ }^{* *} p<0.001$

Figure 5. Mitophagy impairment contributes to GSNOR-deficient hepatocellular carcinoma sensitivity to $\alpha$ TOS. (A) Western blot analysis of GSNOR and Parkin in HUH7 cells transiently downregulating GSNOR (siGSNOR) and/or Parkin (siParkin). Vinculin was used as loading control. (B) Cell viability fluorescent assay performed in HUH7 cells singly or doubly transfected with siGSNOR or siParkin RNAs, and treated with $40 \mu \mathrm{M} \alpha \mathrm{TOS}$. Dead cells were stained with propidium iodide (red), whereas living cells were stained with calcein-AM (green). DMSO was selected as a control. (C) Cell death evaluation as ratio between dead and total cells and expressed as mean \pm SEM of $n=5$ different fields of $\mathrm{n}=3$ independent experiments. ${ }^{* *} p<0.01$; ns $=$ not significant. (D) Western blot analysis of GSNOR and Parkin in HepG2 cells singly or doubly transfected 
with siGSNOR or siParkin RNAs. Vinculin was used as loading control. (E) Analysis of cell viability upon staining with AlamarBlue in the same experimental setting as in (D). DMSO was selected as a control. Viability is expressed as mean \pm SEM of $n=3$ independent experiments in triplicate. ${ }^{*} p<0.05$; ns $=$ not significant. $(\mathbf{F})$ Cell survival analysis of shScr and shGSNOR HepG2 cells in in the same experimental setting as in (D). Afterwards, cells were 5-fold diluted and maintained for 4 additional days in the presence or not of $\alpha$ TOS. Cells were fixed and stained with Crystal Violet at the end of the treatment. Representative pictures (right) and quantitative analysis (left) of Crystal Violet incorporation, performed after elution in methanol and measured at $595 \mathrm{~nm}$. Data shown represent mean \pm SD of $n$ $=3$ independent experiments. ${ }^{* * *} p<0.001 . \mathrm{ns}=$ not significant.

\section{Figure 6. Working model of mitophagy-dependent $\alpha$ TOS toxicity in GSNOR-deficient}

cancer cells. Nitric Oxide (NO) is a signaling molecule physiologically produced by a class of nitric oxide synthases (NOS). The denitrosylase S-nitrosoglutathione reductase (GSNOR), by reducing the nitrosylated form of glutathione (GSH), S-nitrosoglutathione (GSNO), indirectly controls the extent of $S$-nitrosylated proteins (PSNO) (Upper left). GSNOR downregulation, a condition occurring during aging and in some cancer types, results in the accumulation of PSNOs (Upper right). $\alpha \mathrm{TOS}$, by targeting complex II of the mitochondrial electron transport chain, induces mitochondrial damage that, if not neutralized, could lead to cell death. In GSNOR-proficient cells, the selective recognition and degradation of mitochondria (mitophagy) is fully working and ensures a correct clearance of $\alpha$ TOS-damaged mitochondria (Center left). Damaged mitochondria are labeled by means of polyubiquitination of mitochondrial membrane-associated proteins (e.g. Mitofusin 2, Mfn2; Voltage-dependent anion channel, VDAC), carried out by E3 
protein ubiquitin-ligases, among which Parkin represents one of the best characterized examples. Upon damage, PINK1 recruits Parkin onto mitochondria, this representing the starting point for ubiquitin-based labeling of damaged organelles. These are finally recognized by adaptor proteins (e.g. p62 and LC3); surrounded by a double membrane; engulfed, and degraded by fusing with a lysosome. Removal of defective mitochondria by mitophagy has pro-survival effects and contributes to chemoresistance (Bottom left). On the other hand, when GSNOR is mutated or loss, Parkin is inactivated by S-nitrosylation, becoming inactive and unable to be recruited in the proximity of damaged mitochondria, a condition similar to Parkin-deficient cells. In these conditions, $\alpha$ TOS treatment results in the accumulation of defective mitochondria, finally leading to cell death (Bottom right). 
A $\mathrm{HUH7}$

\section{$\square \operatorname{CCCP} 2.5 \mu \mathrm{M}$ \\ CCCP $5 \mu \mathrm{M}$}

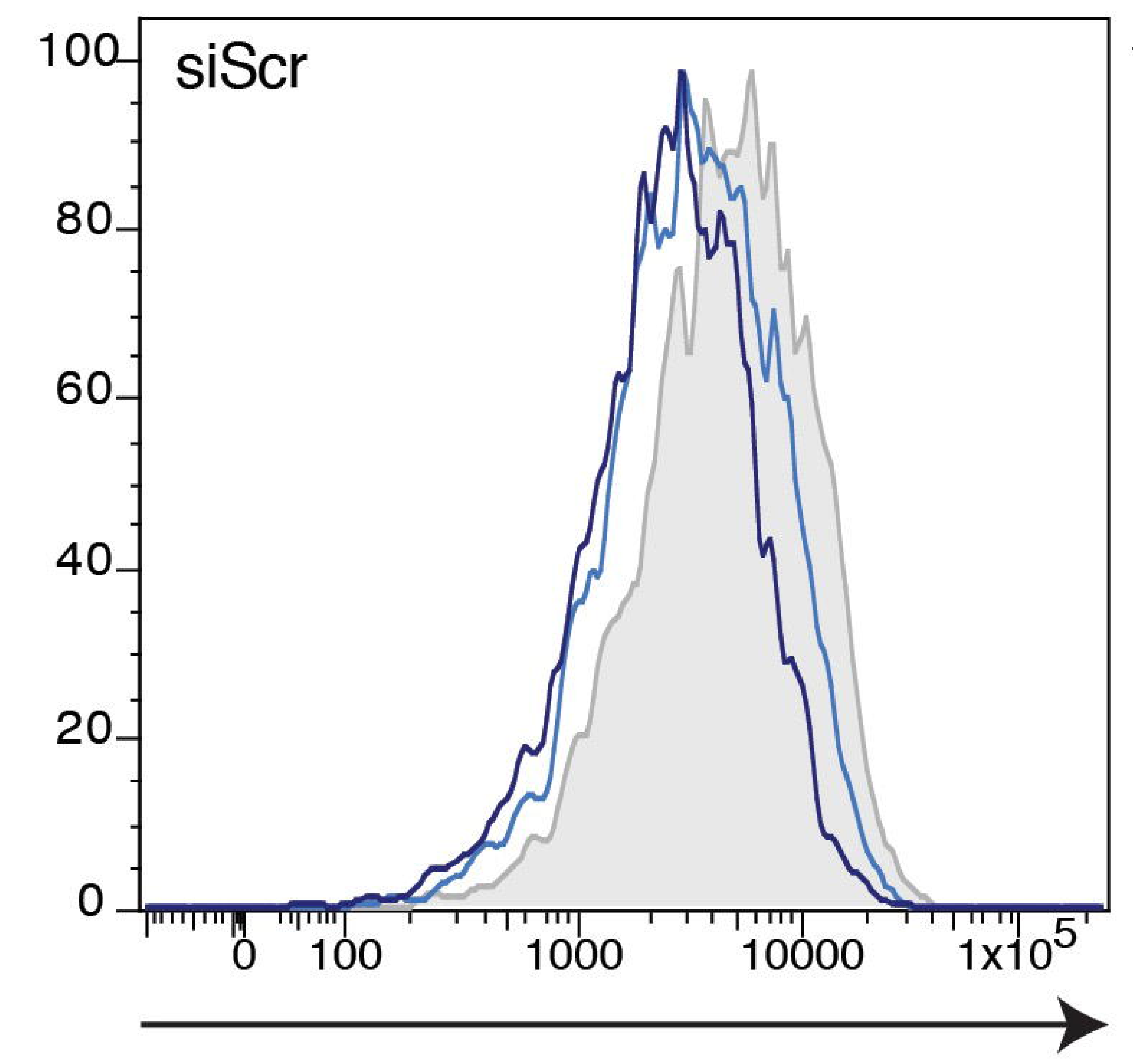

MitoTracker Green Fluorescence

\section{B $\mathrm{HUH7}$}

MitoTracker Green LysoTracker Red Nuclear Violet

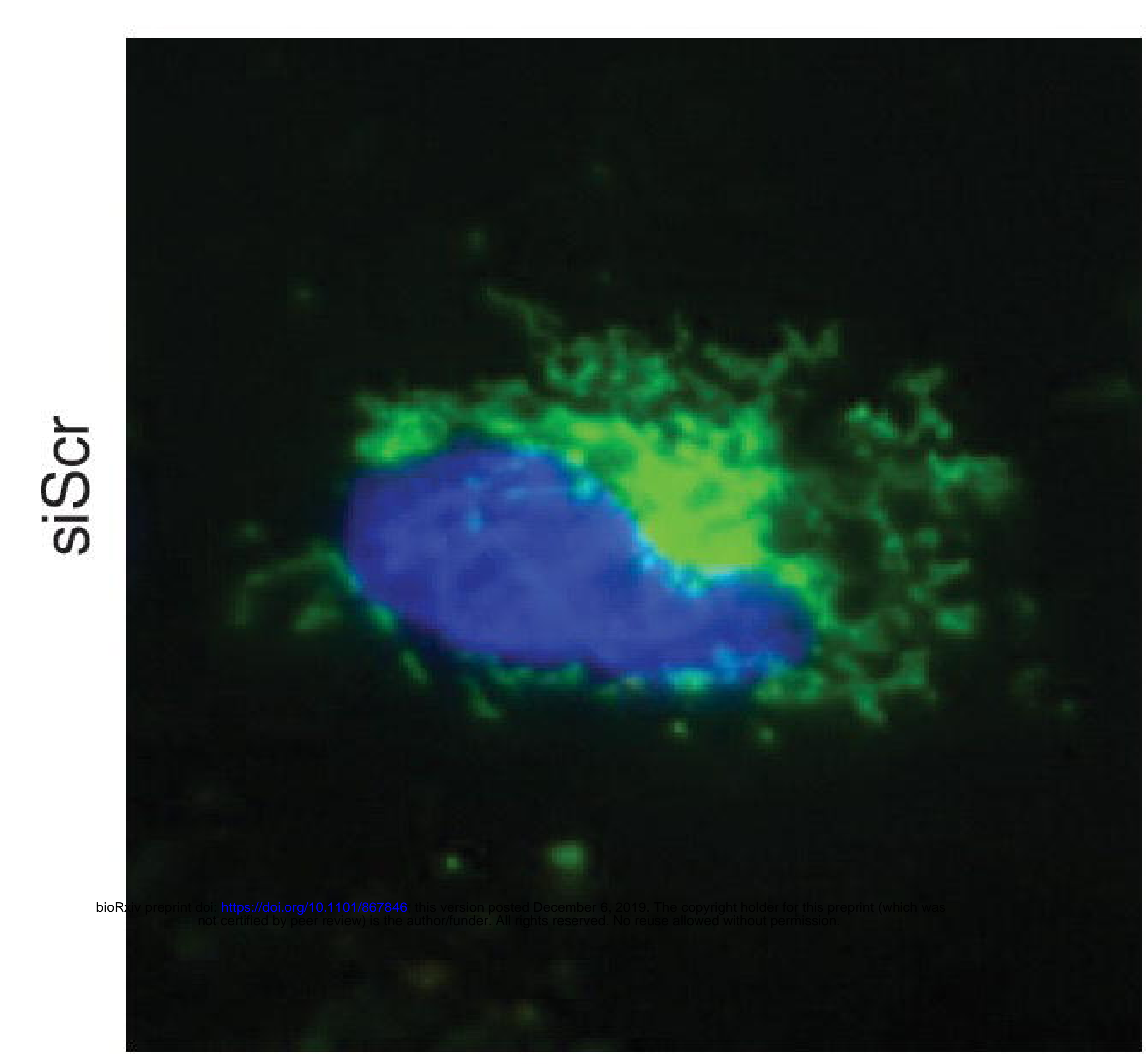

0
0
0
0
0
0
DMSO

CCCP $2.5 \mu \mathrm{M}$

CCCP $5 \mu \mathrm{M}$

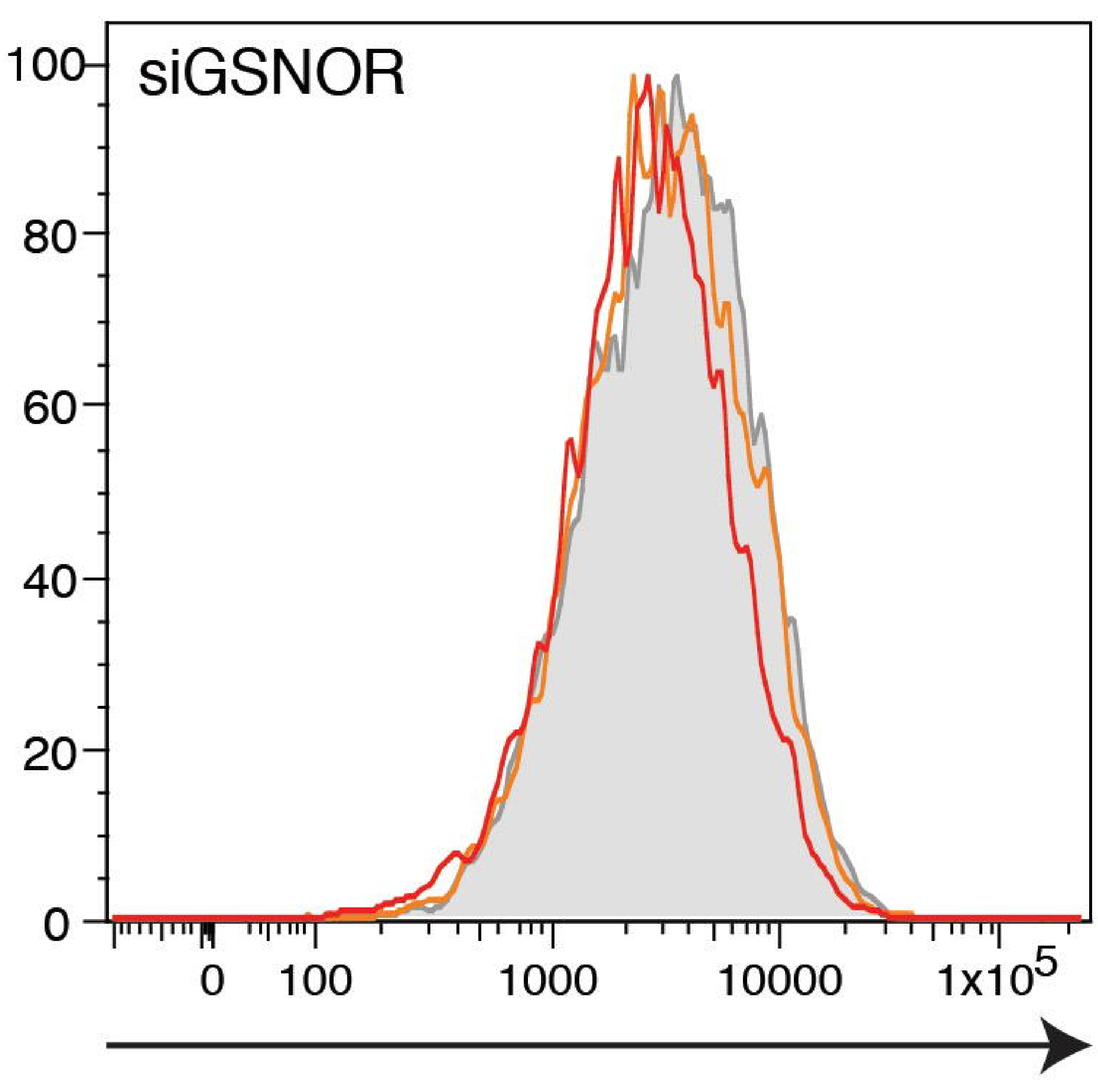

minutes

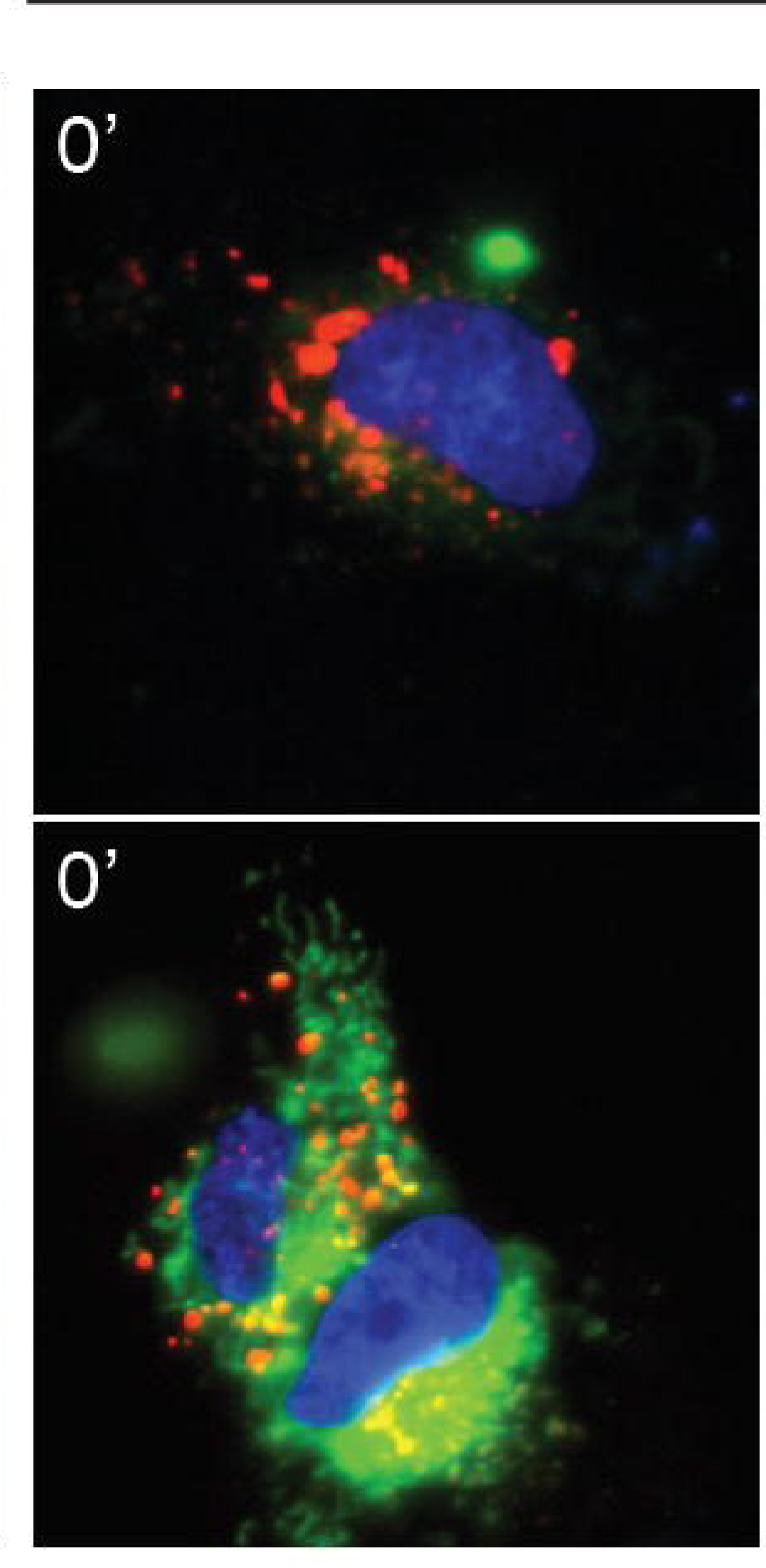

\begin{abstract}
0
\end{abstract}

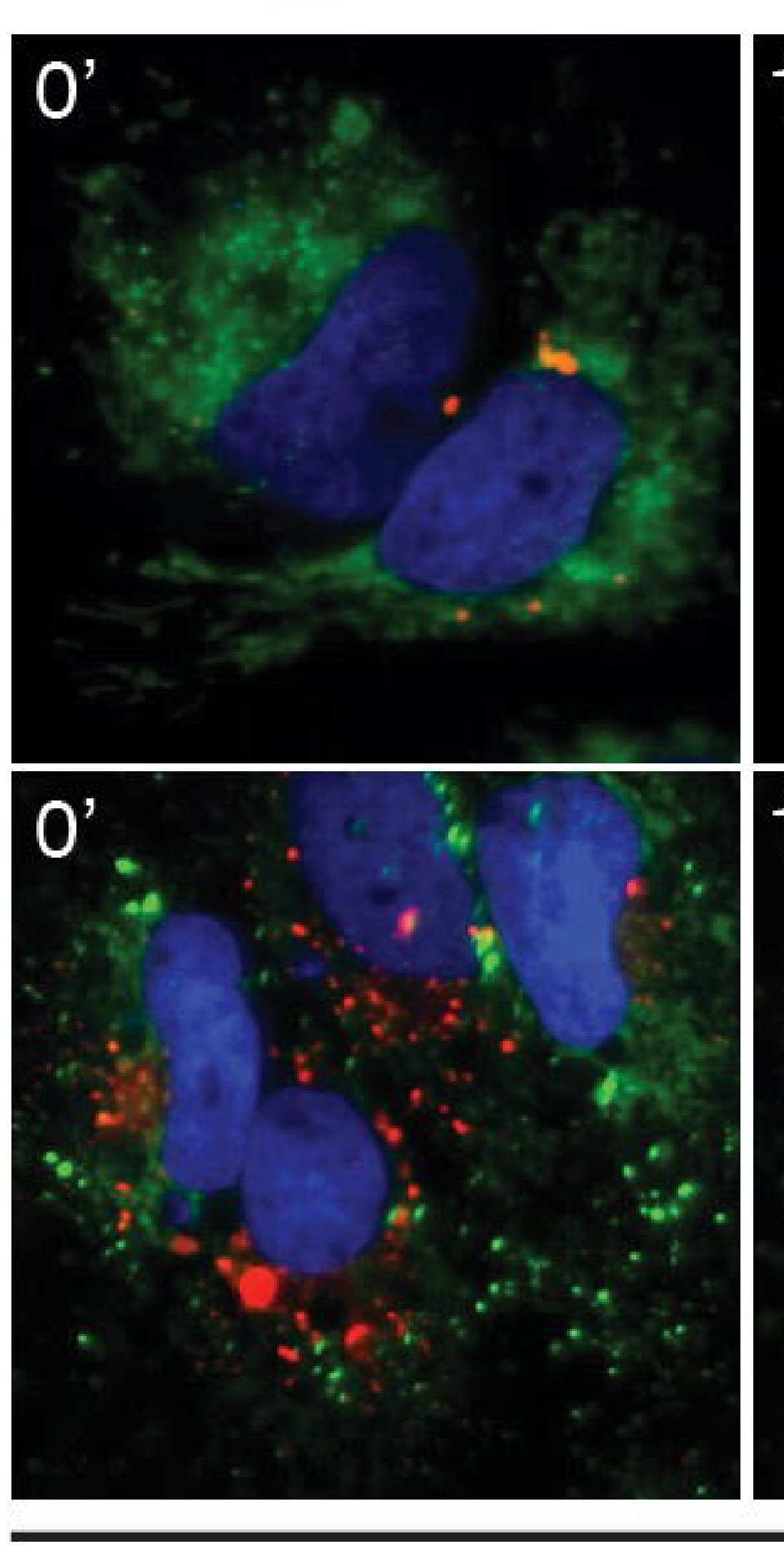

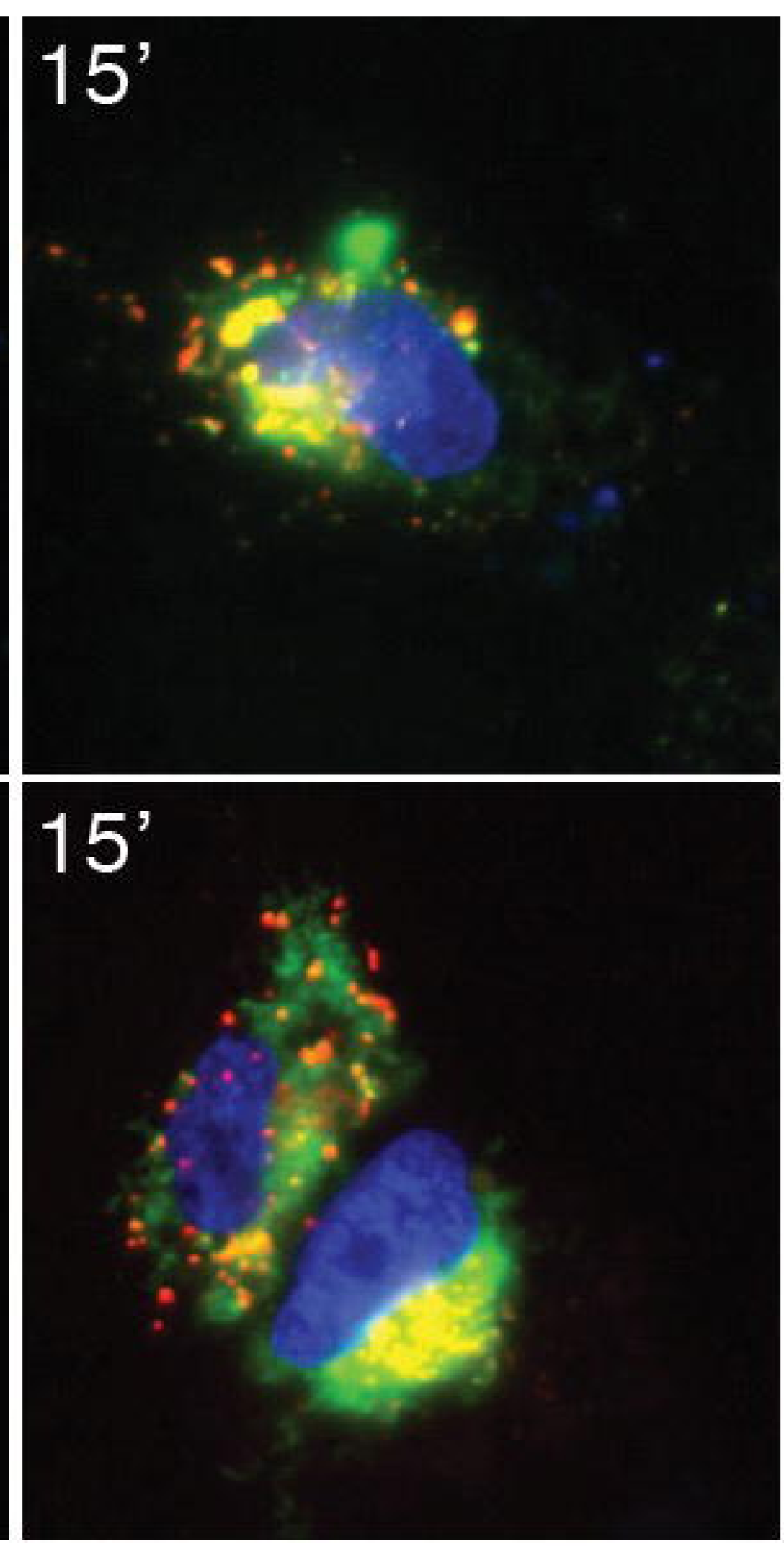

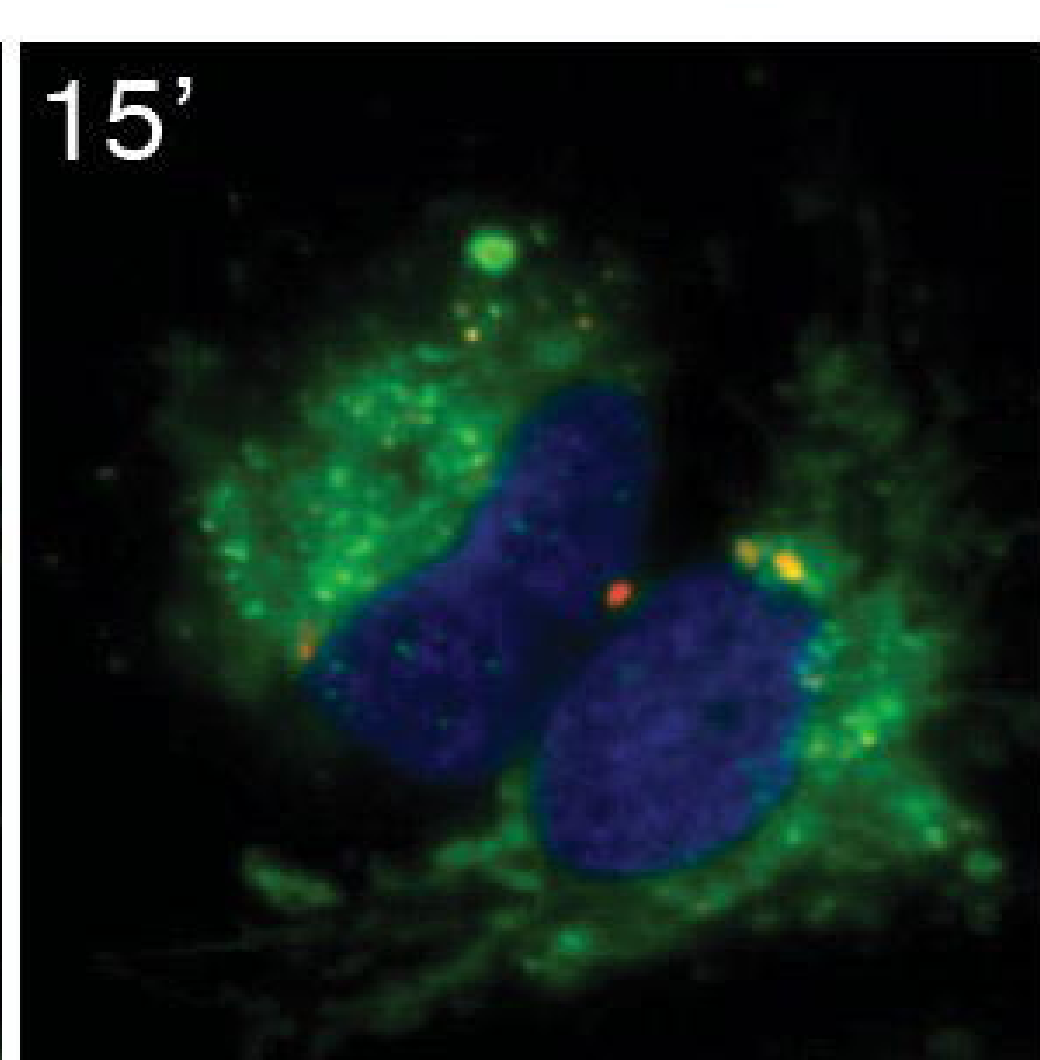

$15^{\prime}$

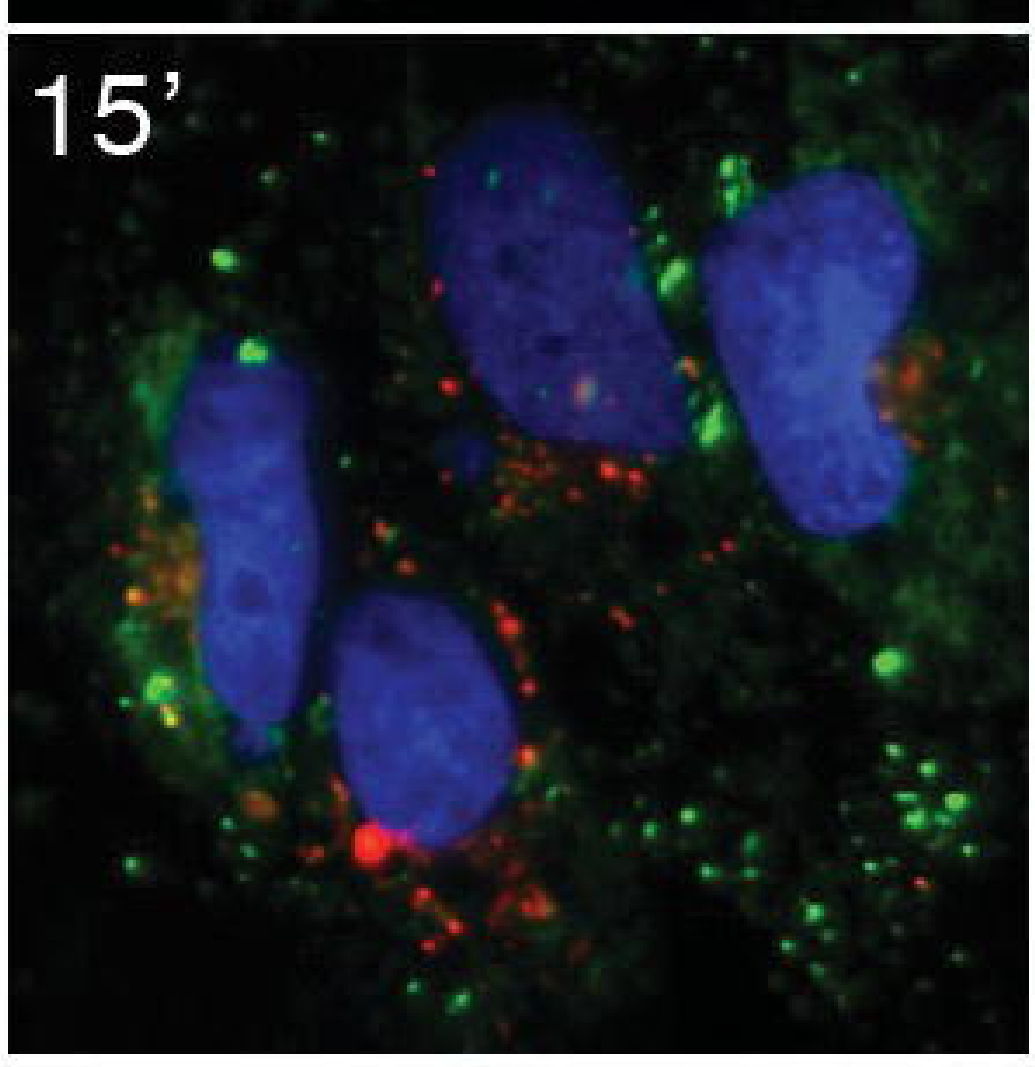

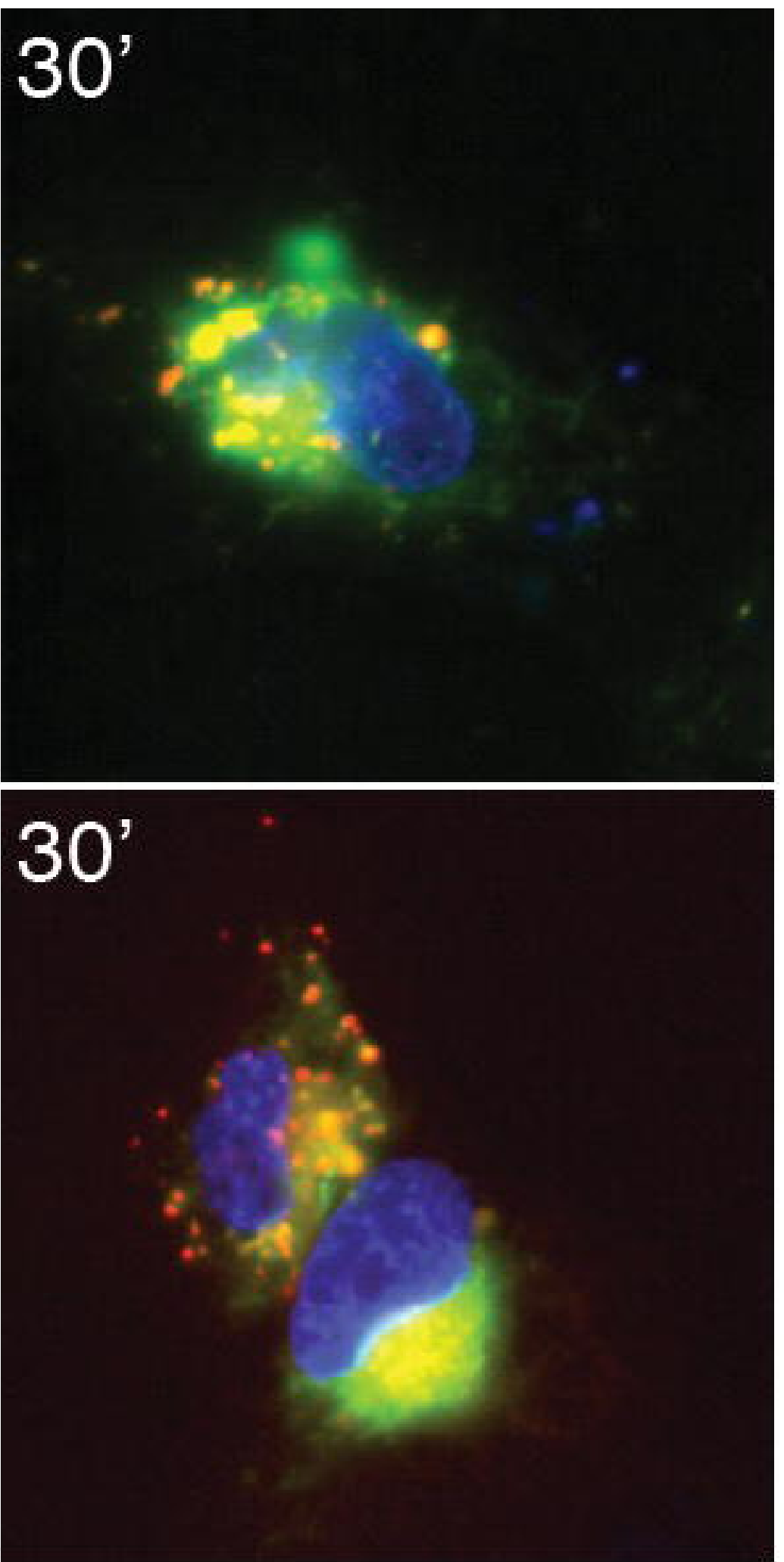

$30^{\prime}$

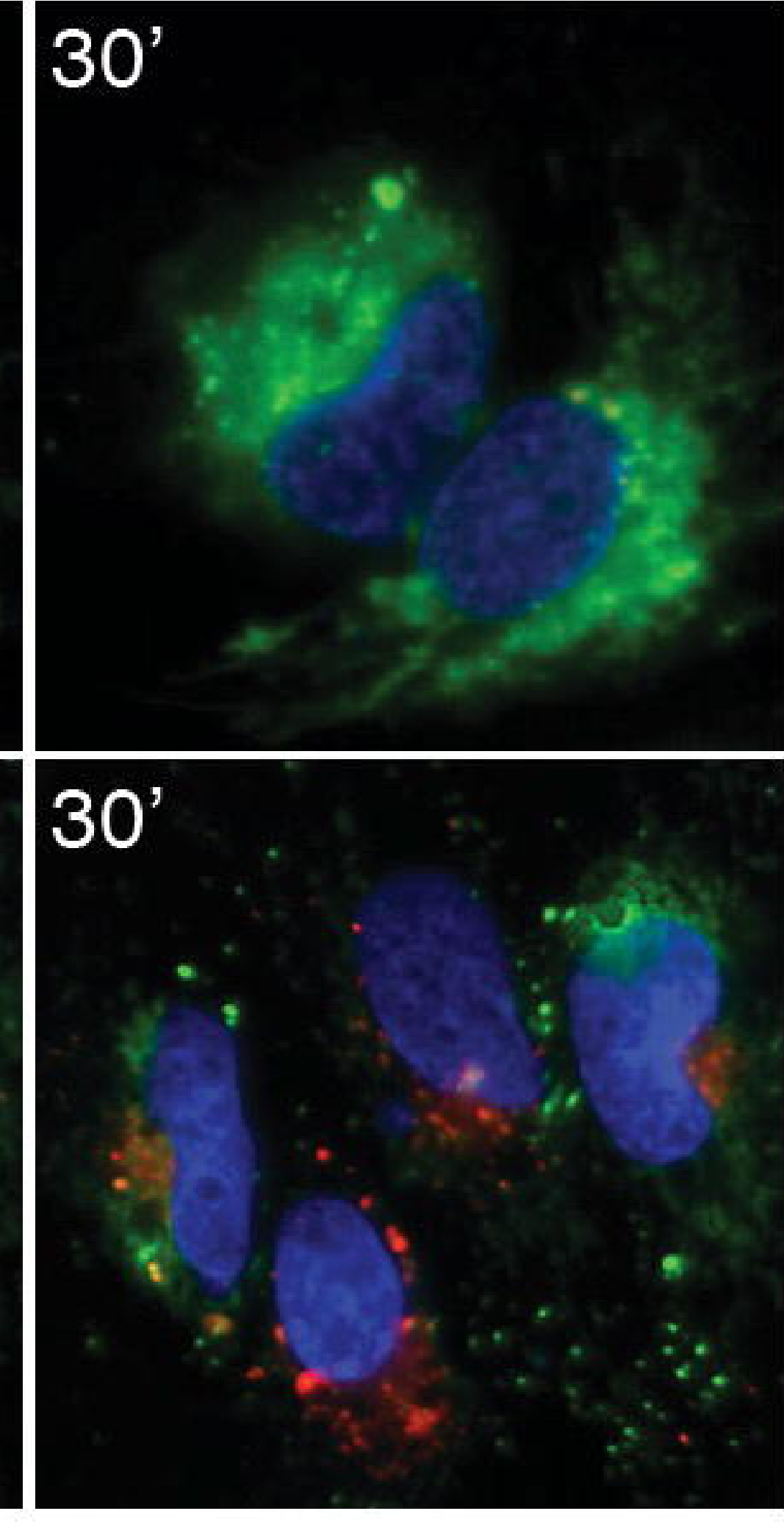

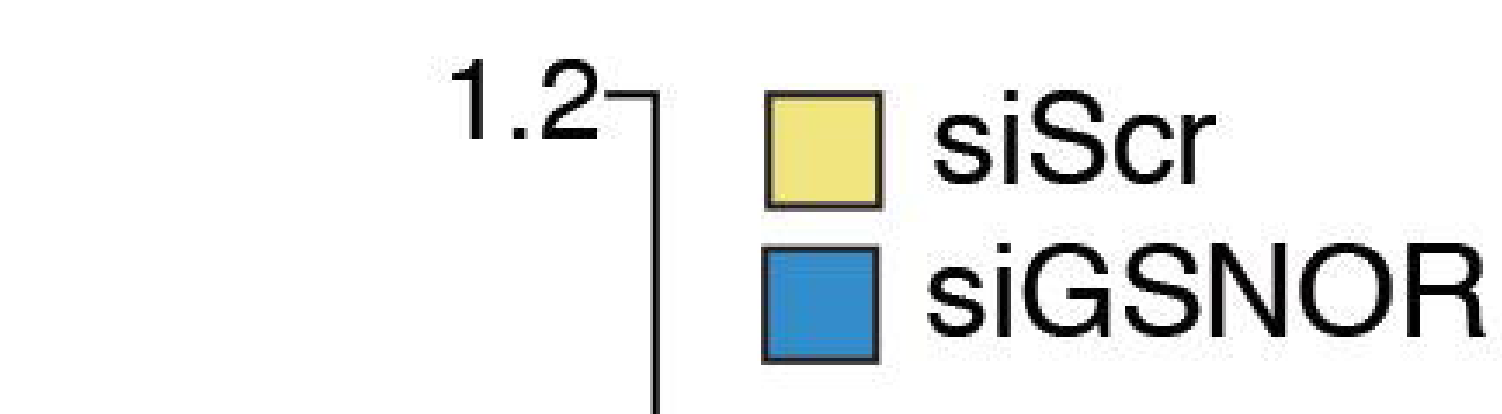

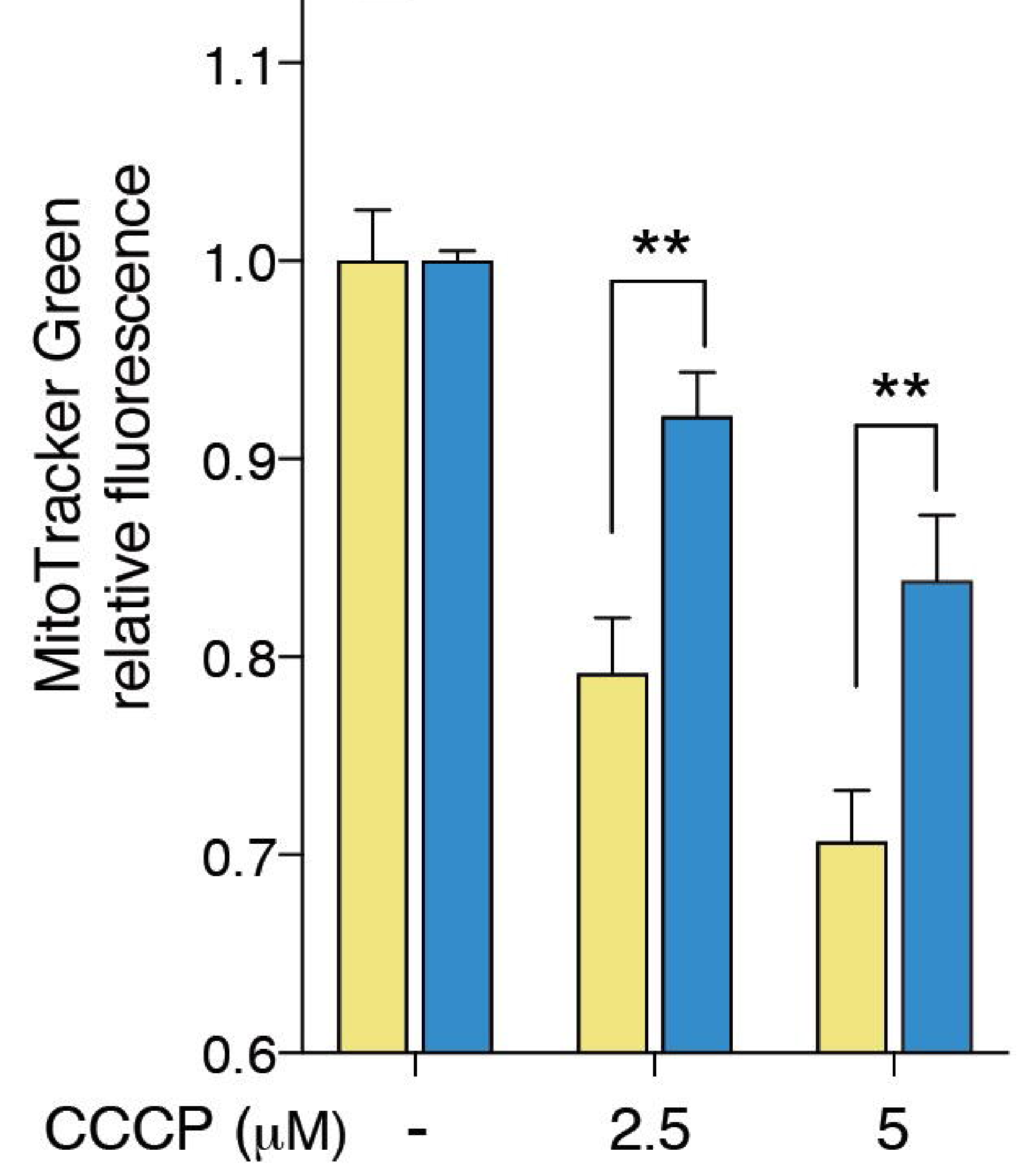

C

HepG2

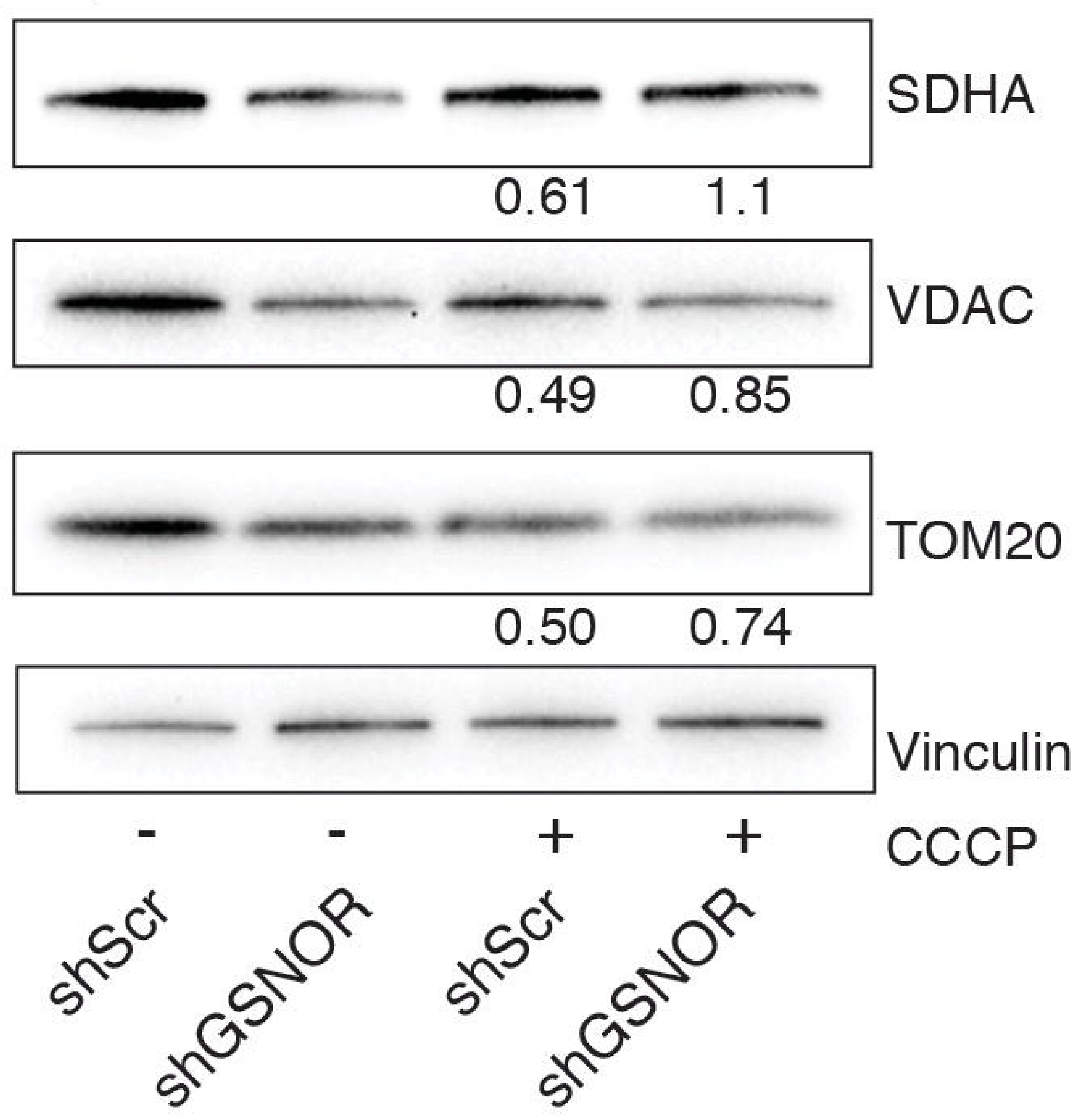



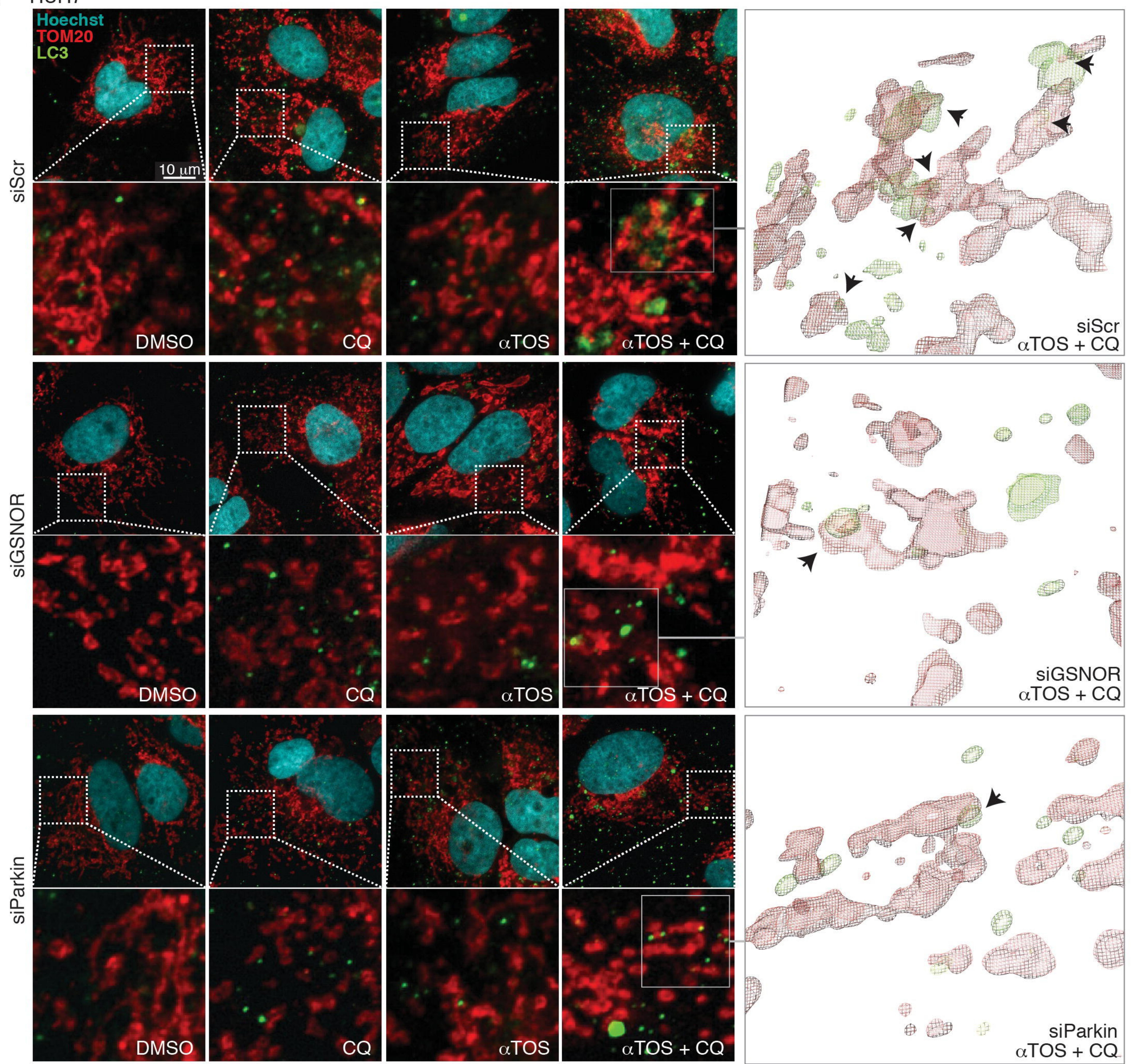

B

OsiScr OsigSNOR OsiParkin

C
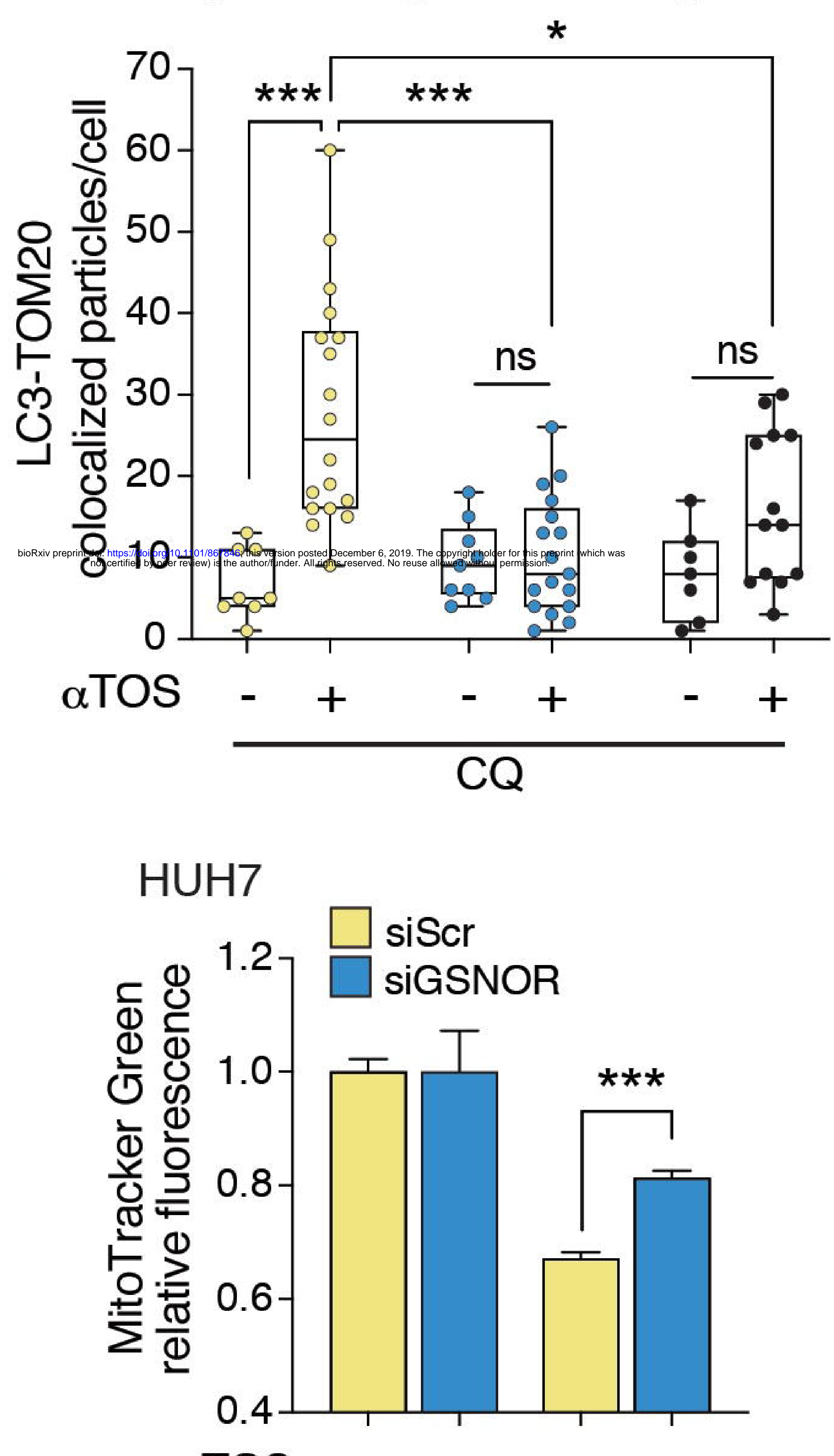

MitoTracker Green LysoTracker Red

Nuclear Violet
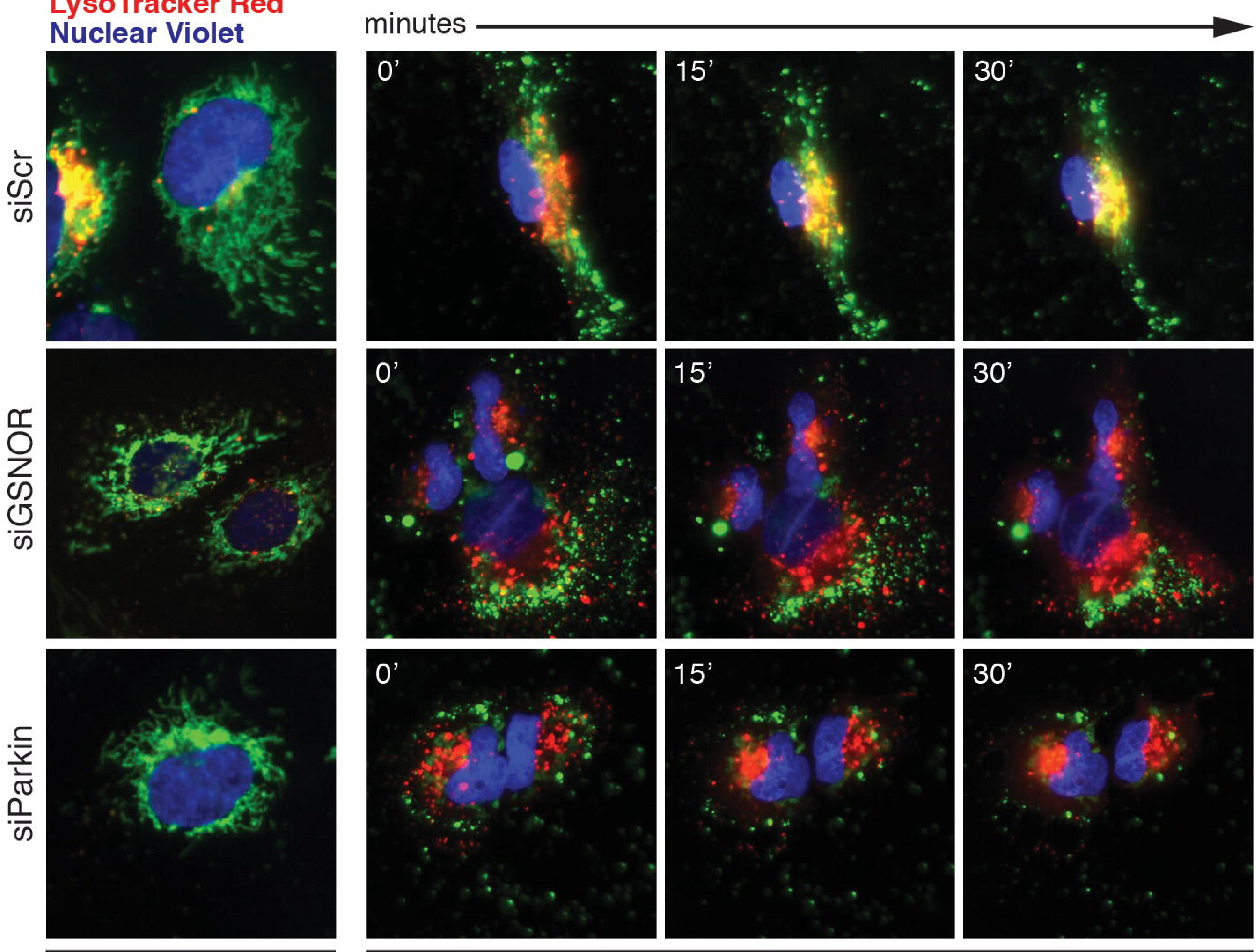
$\mathbf{A}$

$\mathrm{HUH} 7$

\begin{tabular}{|l|l}
\hline$m$ & GSNOR \\
\hline \hline$m \ldots m+m$ & Vinculin
\end{tabular}

Honge wher Parkin

$---\cdots$ Vinculin

- $\quad+\quad+$ siParkin

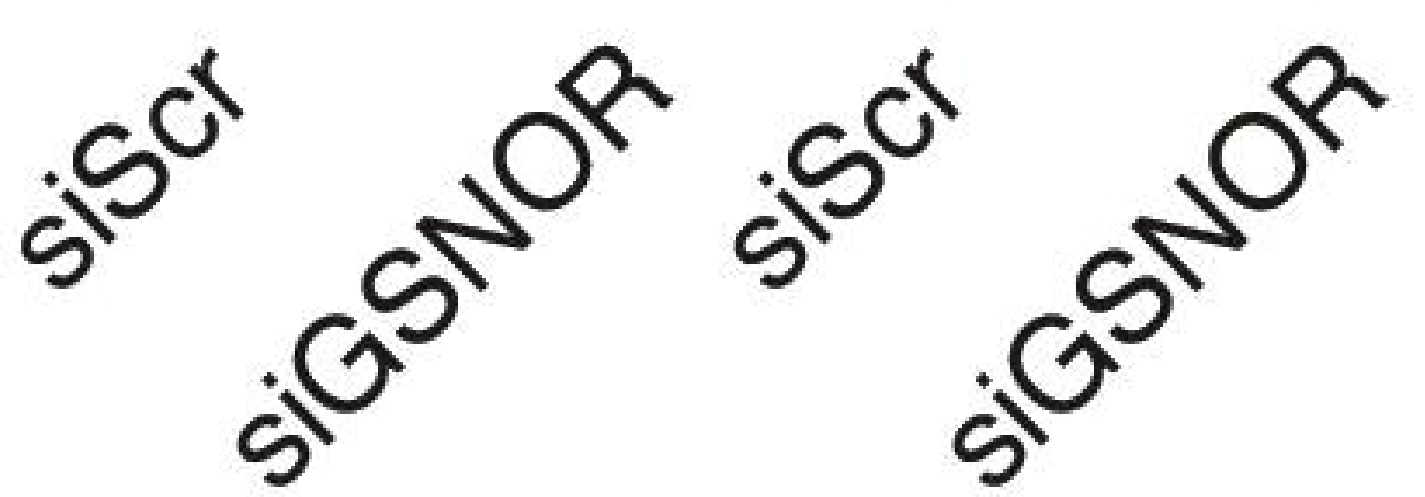

$\mathrm{HUH7}$

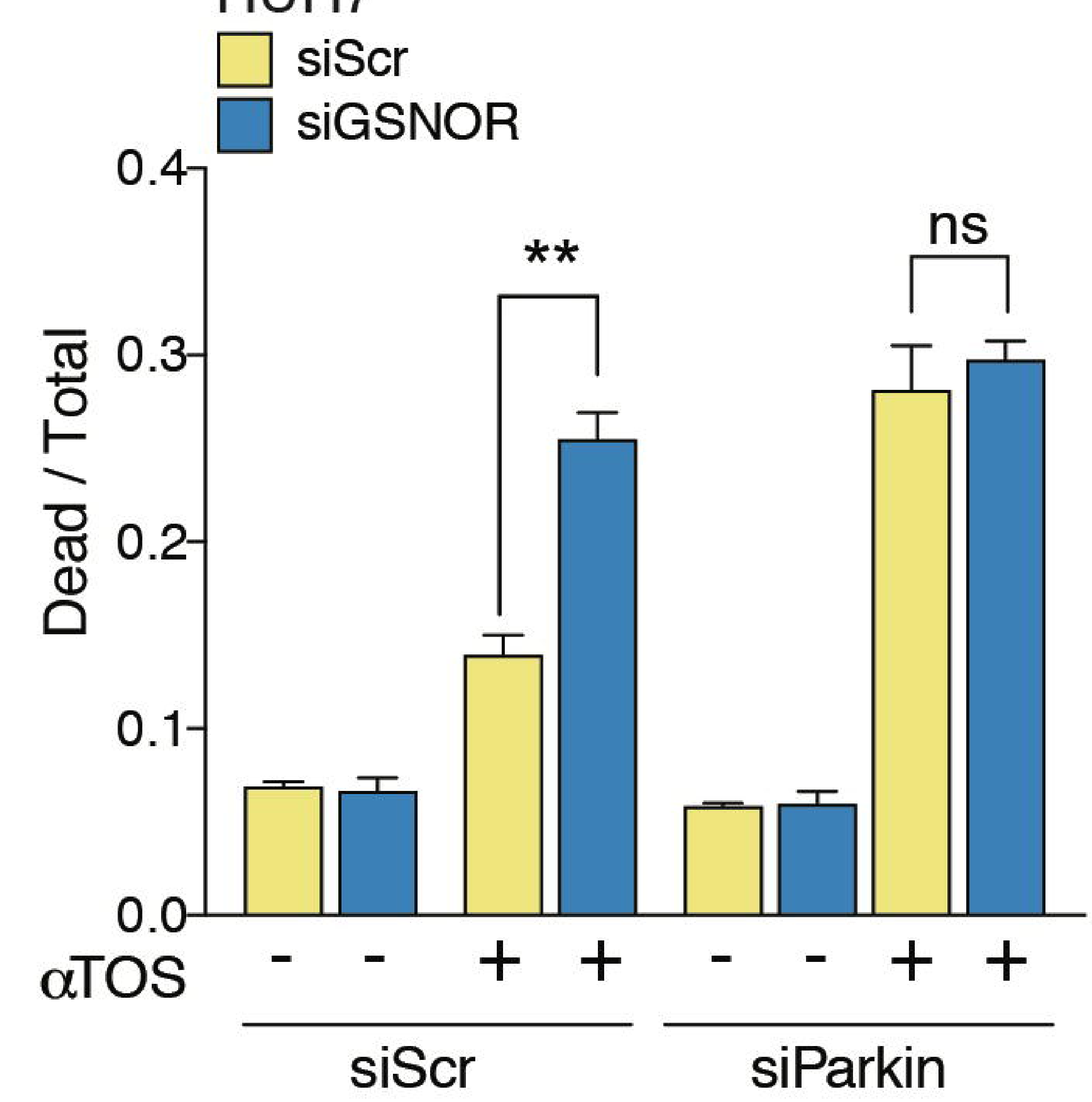

HepG2
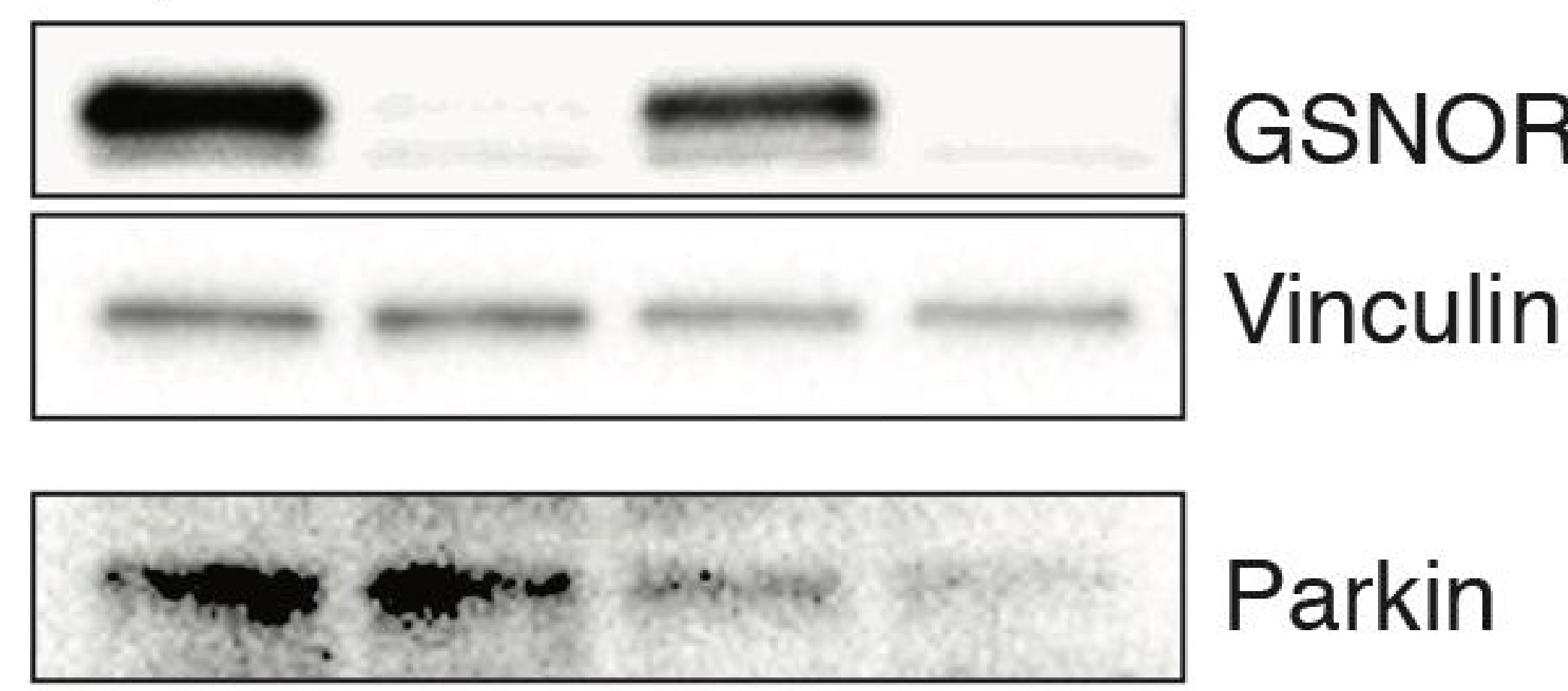

$=--\quad$ Vinculin

$-\quad-+\quad+$ siparkin

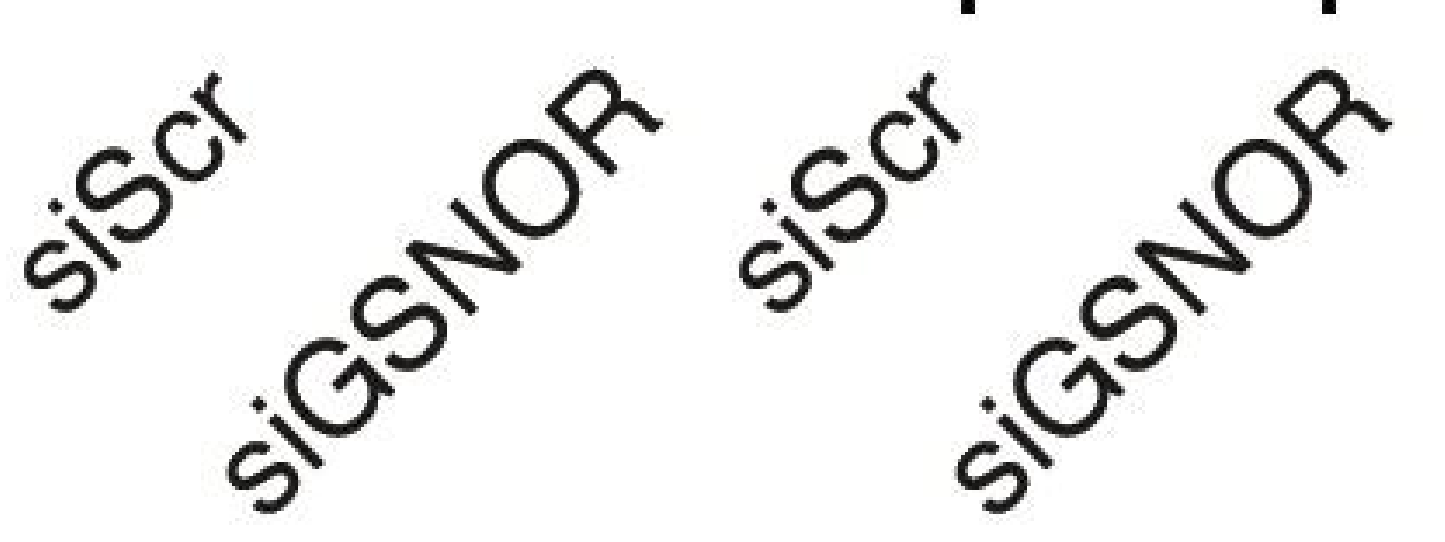

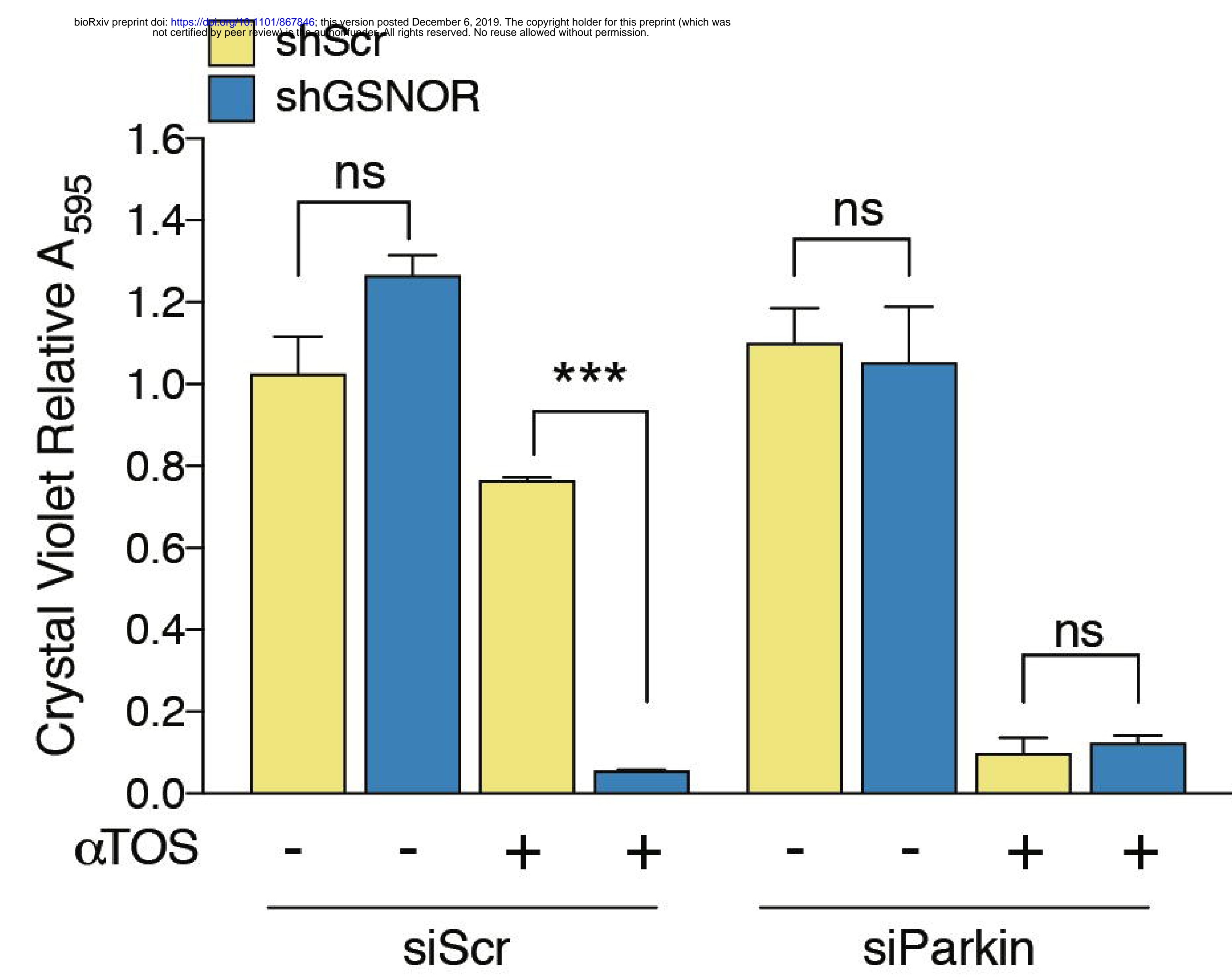

$\frac{\pi}{9}$

B
siScr

siGSNOR
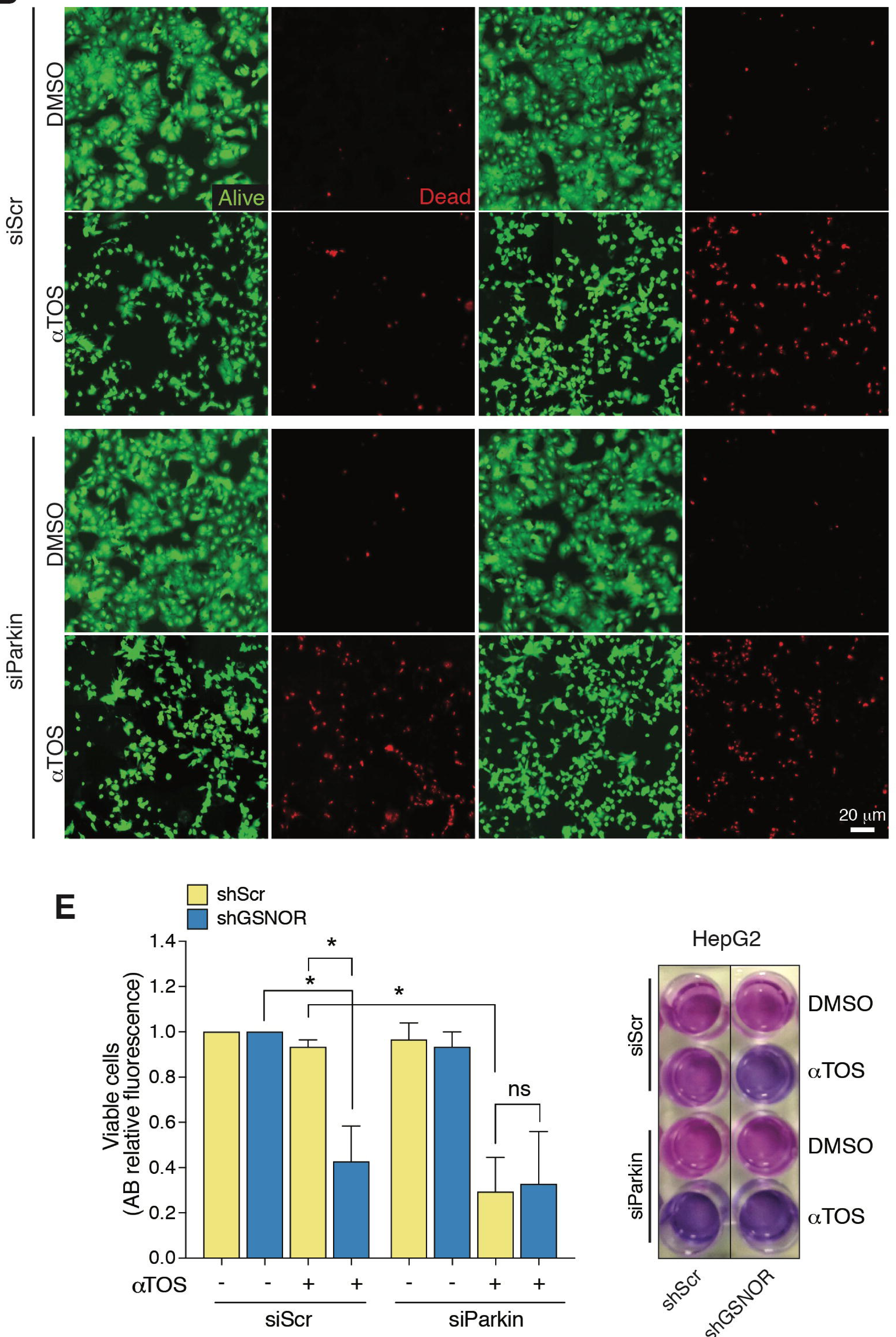

HepG2

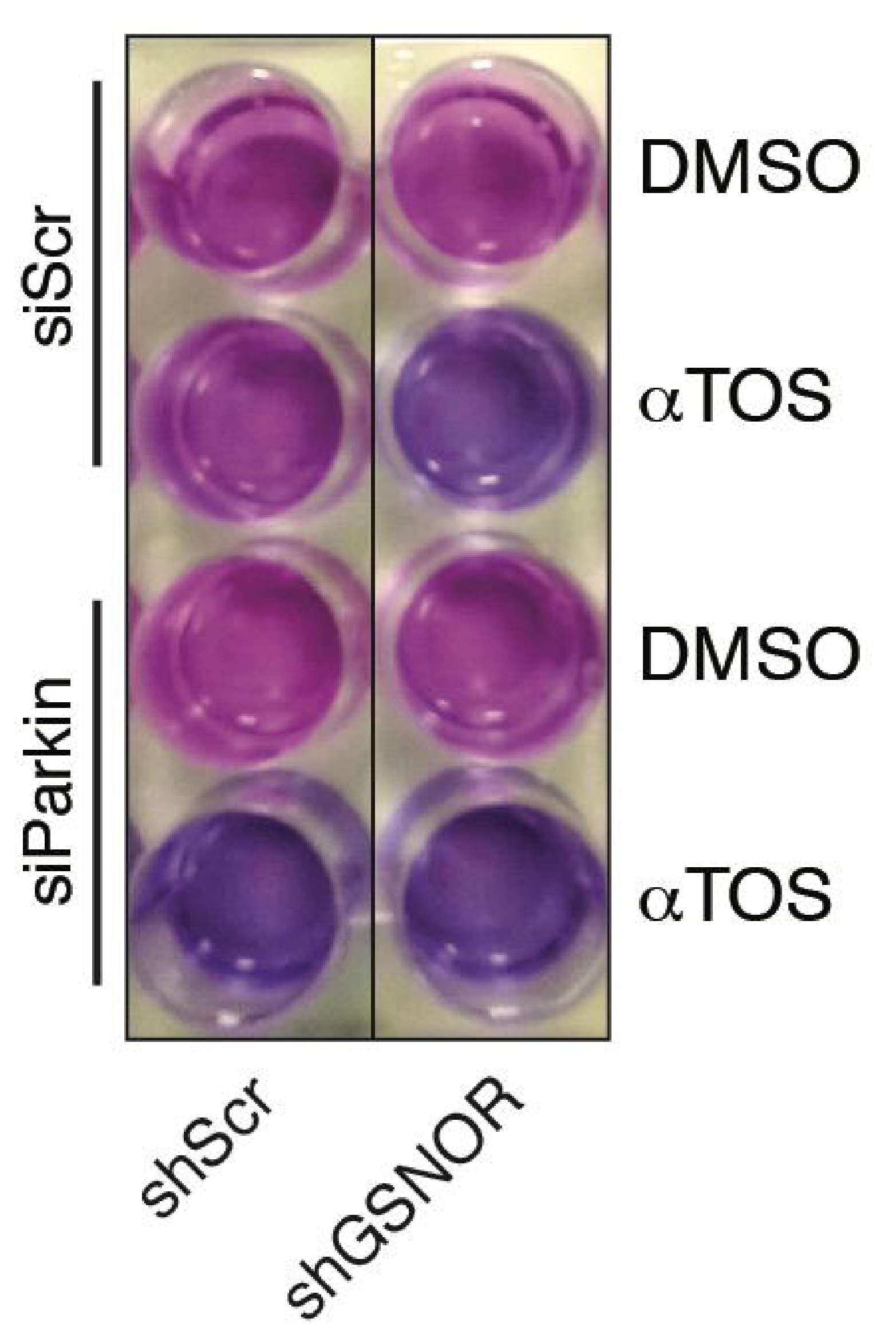

HepG2

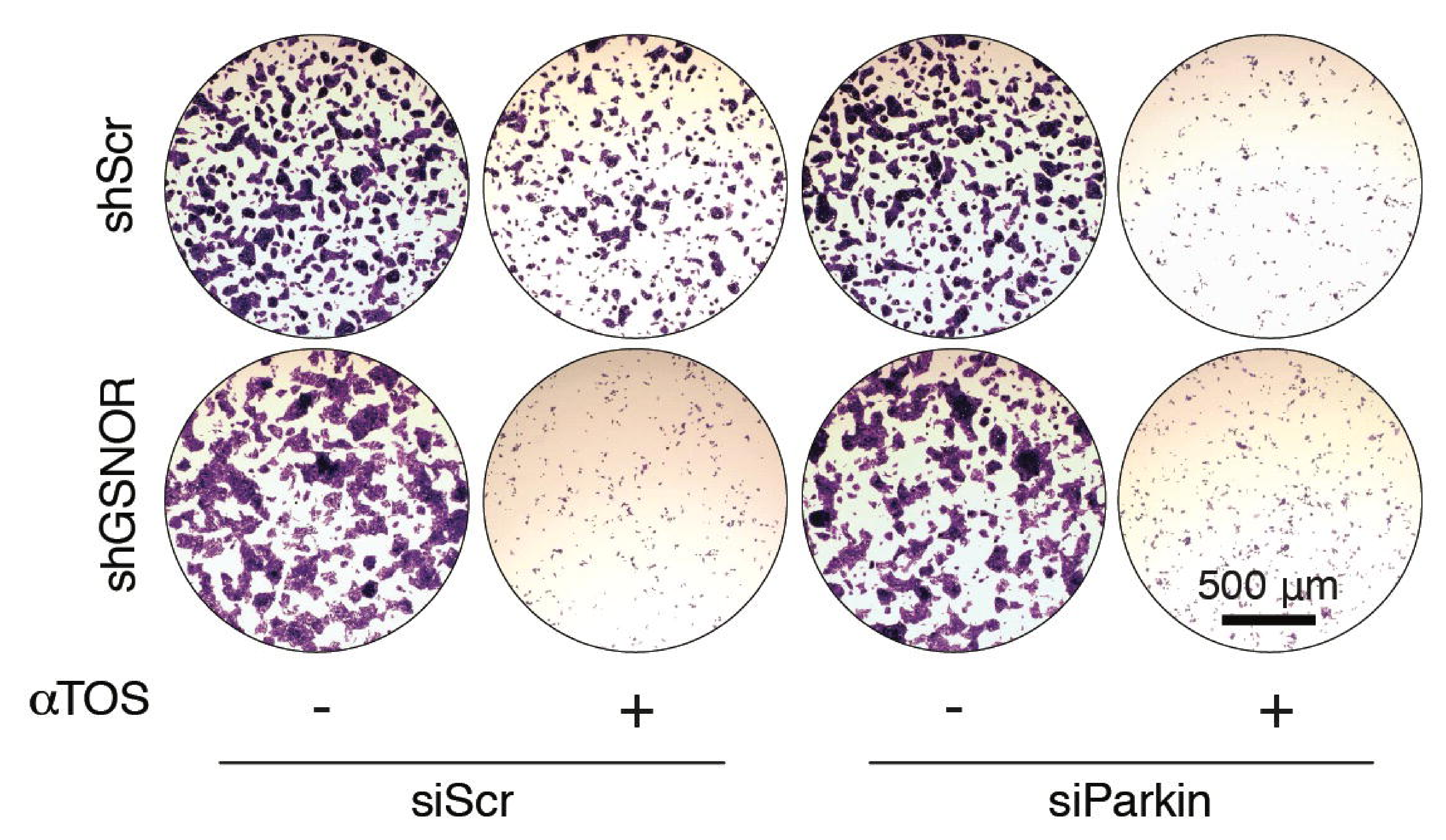




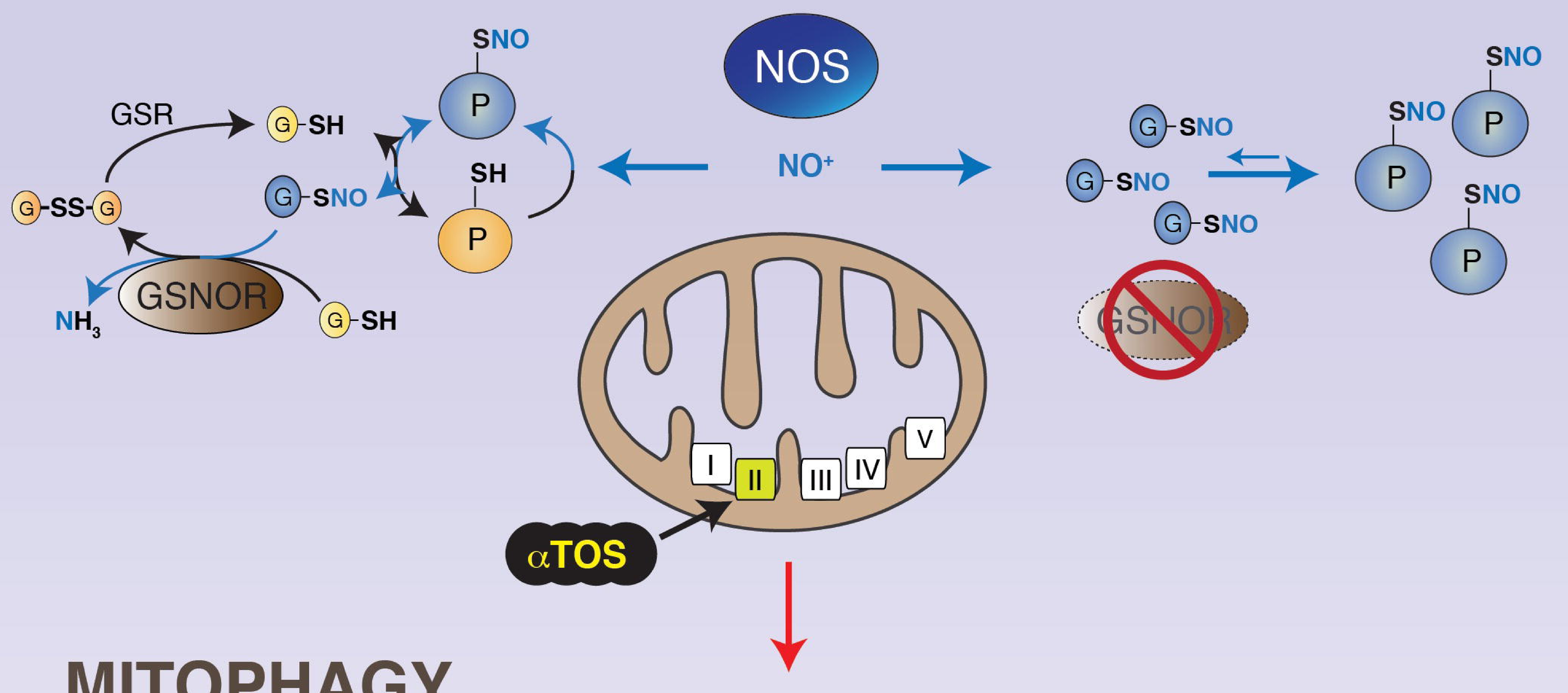

\section{MITOPHAGY}

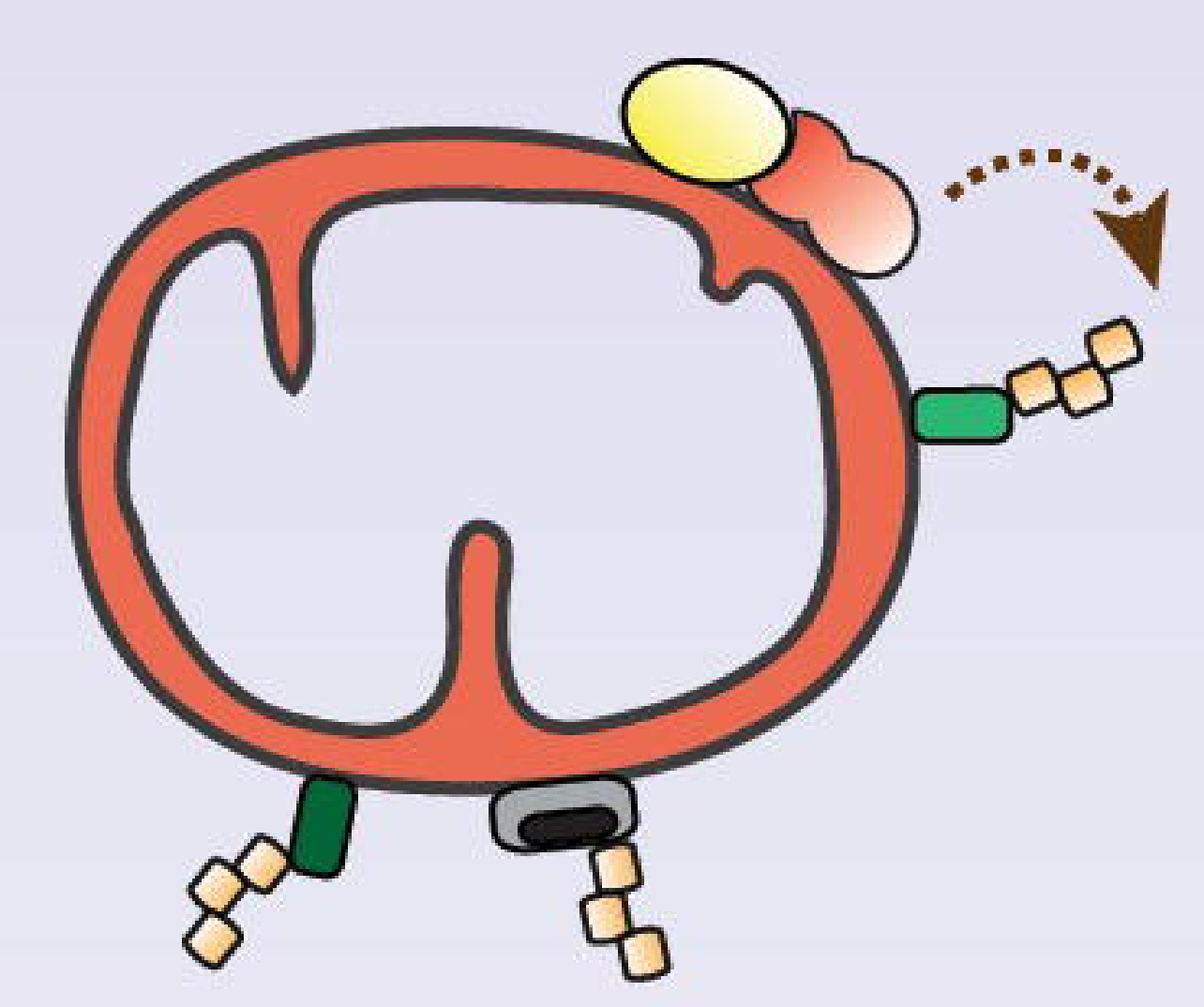

Phagophore
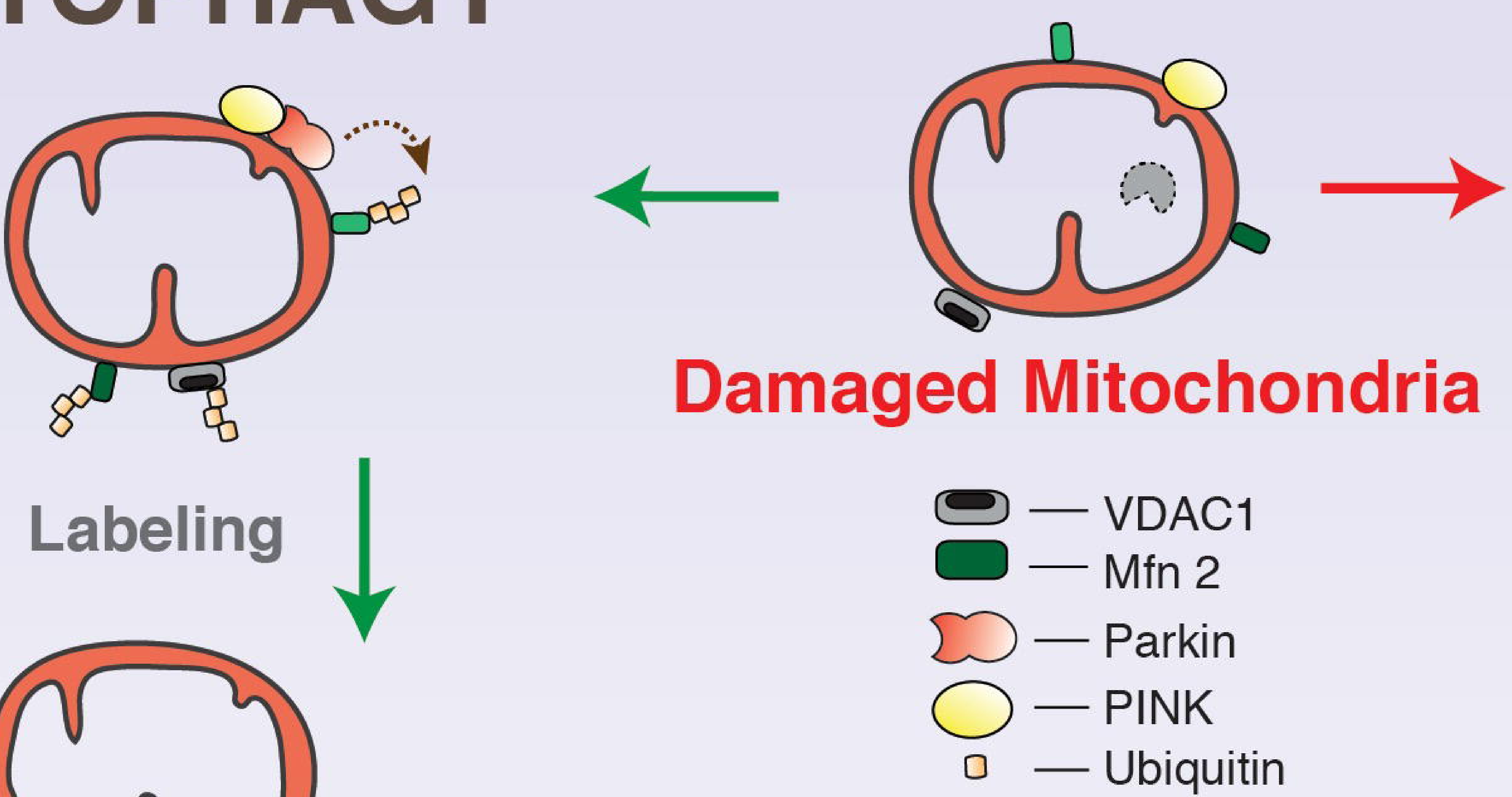

\section{Engulfment}

Poly-ubiquitin
- p62
- LC3
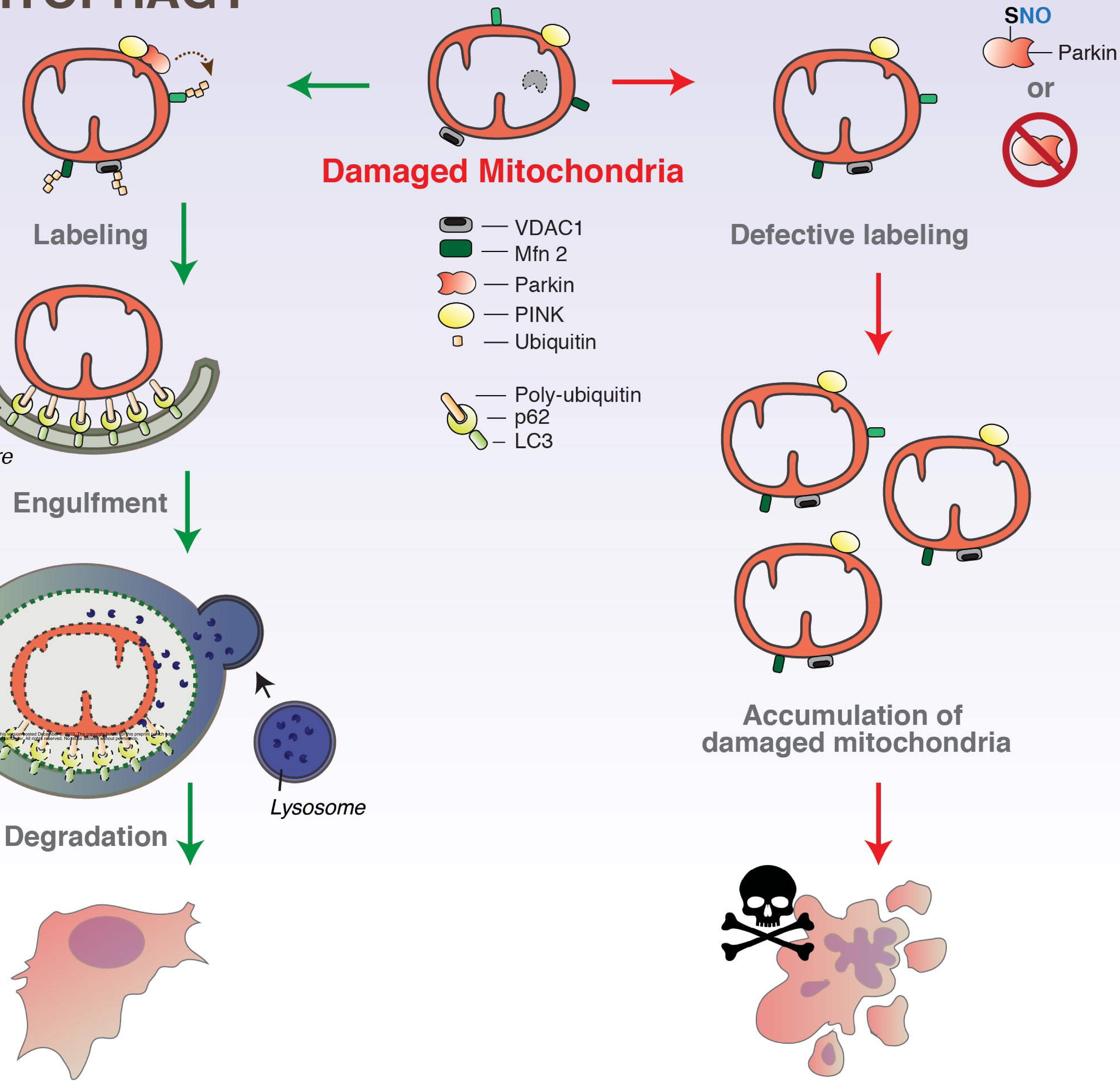

Defective labeling
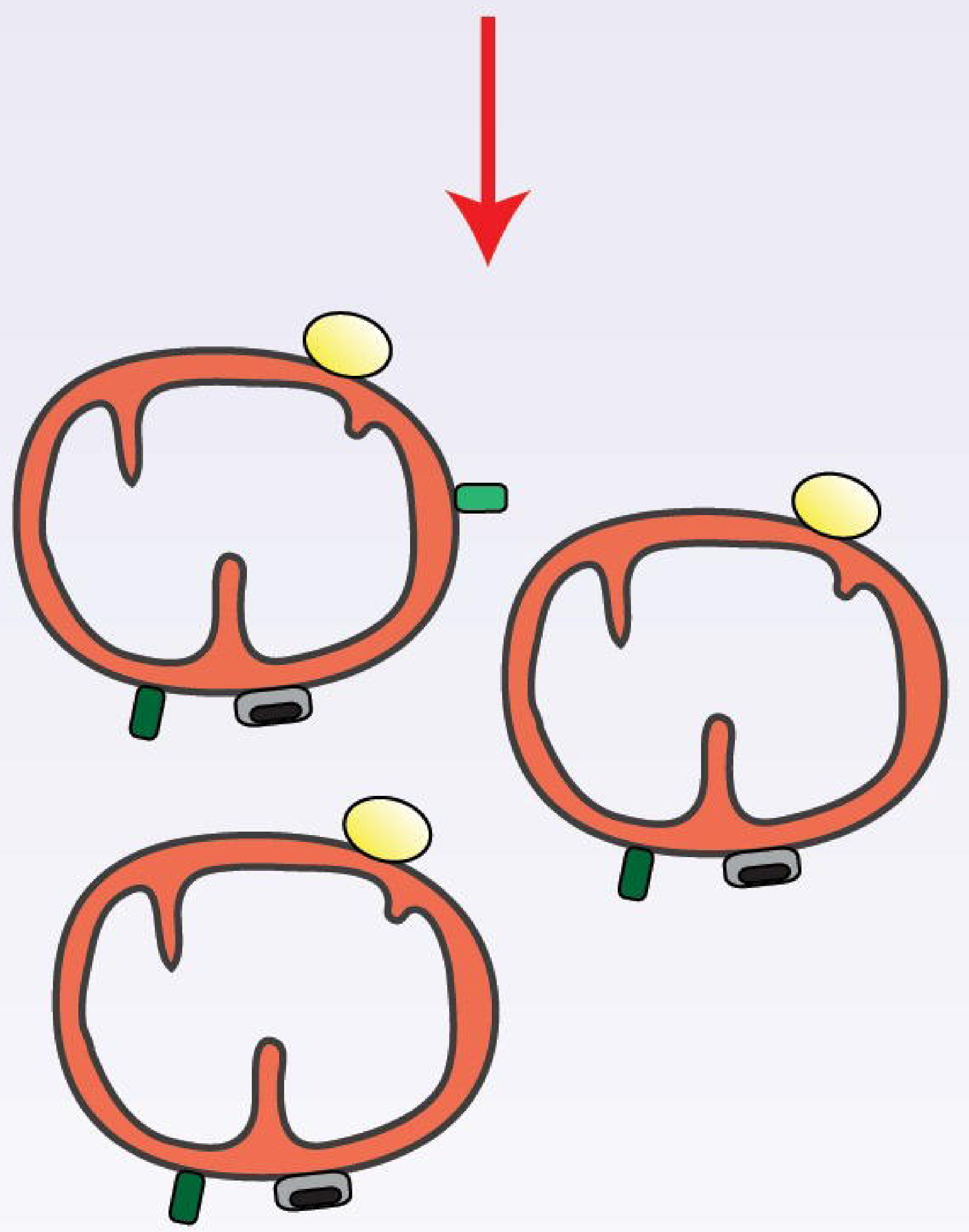

Accumulation of damaged mitochondria

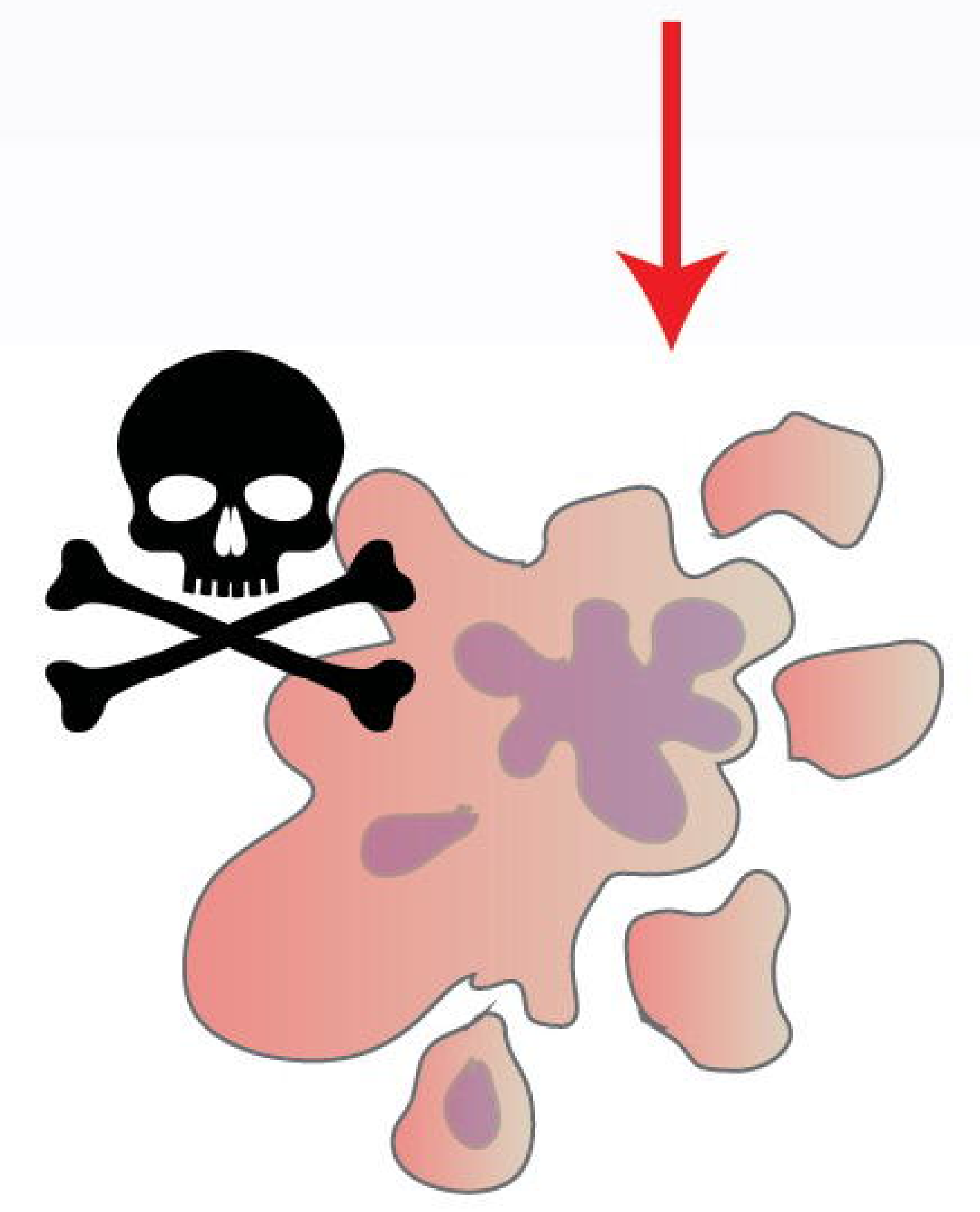

